\title{
Genotypes and population genetics of cryptococcus neoformans and cryptococcus gattii species complexes in Europe and the mediterranean area
}

Massimo Cogliati ${ }^{\mathrm{a}, *}$, Marie Desnos-Ollivier ${ }^{\mathrm{b}}$, Ilka McCormick-Smith ${ }^{\mathrm{c}}$, Volker Rickerts ${ }^{\mathrm{c}}$, Kennio Ferreira-Paim ${ }^{\mathrm{d}, \mathrm{e}}$, Wieland Meyer $^{\mathrm{d}}$, Teun Boekhout ${ }^{\mathrm{f}, g}$, Ferry Hagen ${ }^{\mathrm{f}}$, Bart Theelen ${ }^{\mathrm{f}}$, Joäo Inácio $^{\mathrm{h}}$, Beatriz Alonso ${ }^{\mathrm{h}, \mathrm{i}}$, Maria F. Colom ${ }^{\mathrm{j}}$, Luciana Trilles ${ }^{\mathrm{k}}$, Maria Teresa Montagna ${ }^{1}$, Antonella De Donno $^{\mathrm{m}}$, Serdar Susever ${ }^{\mathrm{n}}$, Cagri Ergin ${ }^{\circ}$, Aristea Velegraki $^{\mathrm{p}}$, Mohamed S. Ellabib ${ }^{\mathrm{q}}$, Simona Nardoni ${ }^{\mathrm{r}}$, Cristina Macci ${ }^{\mathrm{s}}$, Laura Trovato ${ }^{\mathrm{t}}$, Ludovico Dipineto ${ }^{\mathrm{u}}$, Sevim Akcaglar ${ }^{\mathrm{v}}$, Emilija Mlinaric-Missoni $^{\mathrm{w}}$, Sebastien Bertout ${ }^{\mathrm{x}}$, Ana C.F. Vencá ${ }^{\mathrm{y}}$, Ana C. Sampaio ${ }^{\mathrm{z}}$, Giuseppe Criseo $^{\mathrm{aa}}$, Stéphane Ranque ${ }^{\mathrm{ab}}$, Nilgün Çerikçioğlu ${ }^{\mathrm{ac}}$, Anna Marchese ${ }^{\mathrm{ad}}$, Luigi Vezzulli ${ }^{\mathrm{ae}}$, Macit Ilkit $^{\text {af }}$, Vincenzo Pasquale ${ }^{\text {ag }}$, Itzhack Polacheck ${ }^{\text {ah }}$, Shawn R. Lockhart ${ }^{\text {ai }}$

${ }^{\text {a }}$ Dip. Scienze Biomediche per la Salute, Università degli Studi di Milano, Milano, Italy

${ }^{\mathrm{b}}$ Institut Pasteur, Molecular Mycology Unit, National Reference Center for Invasive Mycoses \& Antifungal, CNRS UMR2000, Paris, France

${ }^{\mathrm{c}}$ Robert-Koch Institute, Berlin, Germany

${ }^{\mathrm{d}}$ Molecular Mycology Research Laboratory, Center for Infectious Diseases, Faculty of Medicine and Health, Sydney Medical School, Westmead Clinical School, Marie Bashier Institute for Emerging Infectious Diseases and Biosecurity, University of Sydney, Westmead Hospital, (Research and Educational Network) Westmead Institute for Medical Research, Westmead, NSW, Australia

${ }^{\mathrm{e}}$ Department of Microbiology, Federal University of Triangulo Mineiro, Uberaba, Minas Gerais, Brazil

${ }^{\mathrm{f}}$ Westerdijk Fungal Biodiversity Institute, Utrecht, the Netherlands

${ }^{\mathrm{g}}$ Institute of Biodiversity and Ecosystem Dynamic (IBED), University of Amsterdam, Amsterdam, the Netherlands

${ }^{\mathrm{h}}$ School of Pharmacy and Biomolecular Sciences, University of Brighton, Brighton, UK

${ }^{\mathrm{i}}$ Instituto de Investigación Sanitaria Gregorio Marañón (IisGM), Hospital Gegorio Marañón, Madrid, Spain

${ }^{\mathrm{j}}$ Universidad Miguel Hernández, Alicante, Spain

${ }^{\mathrm{k}}$ FIOCRUZ, Fundaçao Oswaldo Cruz, Rio de Janeiro, Brazil

${ }^{1}$ Università degli Studi di Bari "Aldo Moro", Bari, Italy

${ }^{\mathrm{m}}$ DiSTeBA, Università del Salento, Lecce, Italy

${ }^{\mathrm{n}}$ Cyprus Near East University, Nicosia, Cyprus

${ }^{\circ}$ Pamukkale University, Denizli, Turkey

${ }^{\mathrm{p}}$ Medical School, National and Kapodistrian University of Athens, Athens, Greece

${ }^{\mathrm{q}}$ Medical College University of Tripoli, Tripoli, Libya

${ }^{\mathrm{r}}$ Università di Pisa, Pisa, Italy

${ }^{\mathrm{s}}$ National Research Council, Research Institute on Terrestrial Ecosystems (IRET), Pisa, Italy

${ }^{\mathrm{t}}$ Università degli Studi di Catania, Catania, Italy

${ }^{\mathrm{u}}$ University of Napoli Federico II, Napoli, Italy

${ }^{\mathrm{v}}$ Uludag University, School of Medicine, Bursa, Turkey

${ }^{\mathrm{w}}$ Croatian National Institute of Public Health, Zagreb, Croatia

${ }^{x}$ Unité Mixte Internationale "Recherches Translationnelles sur l'infection à VIH et les Maladies Infectieuses", Université de Montpellier, Montpellier, France

${ }^{\mathrm{y}}$ Instituto de Higiene e Medicina Tropical, Lisbon, Portugal

${ }^{\mathrm{z}}$ Universidade de Trás-os-Montes e Alto Douro, CITAB, Quinta dos Prados, Vila Real, Portugal

${ }^{\text {aa }}$ Department of Chemical, Biological, Pharmaceutical and Environmental Sciences, University of Messina, Italy

${ }^{\mathrm{ab}}$ Aix-Marseille University, IRD, APHM, SSA, VITROME, IHU-Méditerranée Infection, Marseille, France

${ }^{\text {ac }}$ Marmara University, School of Medicine, Istanbul, Turkey

${ }^{\text {ad }}$ Sezione di Microbiologia del DISC, Università di Genova-IRCCS Policlinico San Martino Genova, Genova, Italy

${ }^{\text {ae }}$ Dipartimento di Scienze della Terra, dell'Ambiente e della Vita (DISTAV), Università di Genova, Genova, Italy

af University of Çukurova Sarıçam, Adana, Turkey

${ }^{\text {ag } U n i v e r s i t a ̀ ~ d e g l i ~ S t u d i ~ d i ~ N a p o l i ~ P a r t h e n o p e, ~ N a p o l i, ~ I t a l y ~}$

${ }^{\text {ah }}$ Hadassah-Hebrew University Medical Center, Jerusalem, Israel

${ }^{\text {ai }}$ Centers for Disease Control and Prevention, Atlanta, USA

\footnotetext{
* Corresponding author at: Lab. Micologia Medica, Dip. Scienze Biomediche per la Salute, Università degli Studi di Milano, Via Pascal 36, 20133 Milano, Italy. E-mail address: massimo.cogliati@unimi.it (M. Cogliati).
} 


\section{A R T I C L E I N F O}

\section{Keywords:}

Cryptococcus neoformans

Cryptococcus gattii

MLST

Population genetics

Europe

\begin{abstract}
A B S T R A C T
A total of 476 European isolates (310 Cryptococcus neoformans var. grubii, 150 C. neoformans var. neoformans, and 16 C. gattii species complex) from both clinical and environmental sources were analyzed by multi-locus sequence typing. Phylogenetic and population genetic analyses were performed. Sequence analysis identified 74 sequence types among C. neoformans var. neoformans (VNIV), 65 among C. neoformans var. grubii (56 VNI, 8 VNII, 1 VNB), and 5 among the $C$. gattii species complex (4 VGI and 1 VGIV) isolates. ST23 was the most frequent genotype (22\%) among VNI isolates which were mostly grouped in a large clonal cluster including $50 \%$ of isolates. Among VNIV isolates, a predominant genotype was not identified. A high percentage of autochthonous STs were identified in both VNI (71\%) and VNIV (96\%) group of isolates. The 16 European C. gattii species complex isolates analyzed in the present study originated all from the environment and all belonged to a large cluster endemic in the Mediterranean area. Population genetic analysis confirmed that VNI group of isolates were characterized by low variability and clonal expansion while VNIV by a higher variability and a number of recombination events. However, when VNI and VNIV environmental isolates were compared, they showed a similar population structure with a high percentage of shared mutations and the absence of fixed mutations. Also linkage disequilibrium analysis reveals differences between clinical and environmental isolates showing a key role of PLB1 allele combinations in host infection as well as the key role of $L A C 1$ allele combinations for survival of the fungus in the environment. The present study shows that genetic comparison of clinical and environmental isolates represents a first step to understand the genetic characteristics that cause the shift of some genotypes from a saprophytic to a parasitic life style.
\end{abstract}

\section{Introduction}

The encapsulated basidiomycetes yeasts belonging to Cryptococcus neoformans and Cryptococcus gattii species complexes are important pathogens causing cryptococcosis, a fungal infection affecting primarily immunocompromised hosts. Cryptococcosis is acquired from the environment by exposure of the host to sources contaminated by the fungus such as soil, plant materials, and bird excreta. Dehydrated blastospores and basidiospores produced by the fungus are able to reach pulmonary alveoli and may cause a systemic disease by hematogenous dissemination. Cryptococcal yeasts are also able to cross the bloodbrain barrier and cause meningitis and menigo-encephalitis that leads to host death unless treated (Kwon-Chung et al., 2014). Both C. neoformans and C. gattii have been recognized as species complexes each containing several lineages that are object of investigation for their differences in genetic, pathogenic, epidemiological, and ecological characteristics as well as their clinical manifestations. At present, five major molecular types have been recognized within the $C$. neoformans species complex: VNI, VNII, and VNB, all presenting the capsular antigen A (serotype A) and classified as C. neoformans var. grubii; VNIV presenting the capsular antigen D (serotype D) and classified as $C$. neoformans var. neoformans; and VNIII which represents diploid and aneuploid hybrids between the two varieties (AD hybrids). Cryptococcus gattii species complex includes at least four molecular types, VGI (serotype B), VGII (serotype B), VGIII (serotype B or C) and VGIV (majority of serotype C) (Meyer et al., 2003, 2009). Since molecular typing has been performed for only a small percentage of isolates (about 10\%) of the more than 68,000 isolates reported in the literature (Cogliati, 2013), it is likely that additional lineages will be found as more strains are typed and their relationship with existing lineages are analyzed. Hence the names "C. neoformans species complex" and "C. gattii species complex" have been proposed to indicate that both species contain genetically diverse lineages but it is premature to draw boundaries between lineages to warrant each lineage as separate species. The status of "species complex" was provisional for the sake of nomenclatural stability until the vast majority of cryptococcal populations is analyzed and the character of each lineage becomes readily identifiable (KwonChung et al., 2017). The proposed 'species complex' was in response to an earlier proposal for a revision of cryptococcal taxonomy which was based on the currently identified major lineages (Hagen et al., 2015, 2017). The proposed revised system classifies, the VNI, VNII and VNB molecular types as $C$. neoformans, VNIV as $C$. deneoformans, VNIII as $C$. neoformans $\times C$. deneoformans hybrids; VGI as C. gattii, VGII as C. deteurogattii, VGIII (serotype B and C) as C. bacillisporus, a cluster of VGIII serotype $\mathrm{C}$ as $C$. decagattii, and VGIV as $C$. tetragattii. Although this newly proposed classification system has a merit for the progress in the taxonomy of these pathogens within the genus Cryptococcus, it is premature as it is already encountering some difficulties revealed by the most recent molecular studies. VNII, VNB, VGIII, and VGIV lineages have been understudied in the past and only recently some results indicate them to be highly heterogeneous. The recent study on VNI, VNII, and VNB C. neoformans var. grubii isolates by whole genome sequencing showed that VNB could be further separated in two lineages VNBI and VNBII (Rhodes et al., 2017). Similar findings have been obtained for VGIII and VGIV C. gattii isolates, showing that these also include different lineages (Cogliati et al., 2012a; Firacative et al., 2016; Nyazika et al., 2016).

In Europe, as well as in most of the high-income countries, the number of cases of cryptococcosis has decreased during the last two decades since the introduction of high active anti-retroviral therapy, which has drastically reduced the number of AIDS patients (ecdc. europa.eu/en/publications-data/hivaids-surveillance-europe-2017-

2016-data). On the other hand, the population of patients with other immunocompromising conditions, such as those with transplantation (http://www.transplant-observatory.org/count2), hematological malignancies (Miranda-Filho et al., 2018) or autoimmune diseases (www. niaid.nih.gov/sites/default/files/adccfinal.pdf), are on the rise. Cases of cryptococcosis in these patients are often difficult to diagnose due to the rarity and the different clinical manifestation of the disease (Pappas, 2013; George et al., 2018; Henao-Martìnez et al., 2018; Shuai et al., 2018; Wang et al., 2018; Hamdam et al., 2018; Morse et al., 2018; Florentino et al., 2018; Dioverti et al., 2018; Yamada et al., 2018; Swan and Gottlieb, 2018; Posteraro et al., 2018). Furthermore, cryptococcosis can also occur in immunocompetent hosts, especially when the infection is caused by $C$. gattii species complex VGI or VGII, making the diagnosis more complicated (Chen et al., 2014). Early diagnosis is critical for effective therapy and patient management while delayed diagnosis could hamper the therapeutic trajectory and increase the risk of death.

In Europe, most cases of cryptococcosis are caused by isolates of the C. neoformans species complex with VNI being the most prevalent molecular type, followed by VNIV, and VNIII hybrids (Viviani et al., 2006; Cogliati, 2013; Sanchini et al., 2014; Desnos-Ollivier et al., 2015). A higher prevalence of VNIV, and consequently of VNIII hybrids, than in other continents is a peculiar characteristic of Cryptococcus epidemiology in Europe (Cogliati, 2013). A recent niche modeling analysis suggested that VNIV isolates are well adapted to European climatic conditions characterized by areas with sub-continental climate, which provides the optimal ecological niche for this pathogen (Cogliati 
et al., 2017). Furthermore, VNIII isolates resulting from hybridization of VNI and VNIV genotypes could play an important role in the evolution of the $C$. neoformans species complex since it represents a mechanism of generating new genetic variability and therefore potentially highly virulent strains (Sun and Xu, 2009; Shahid et al., 2008; Cogliati et al., 2012b).

Cases of cryptococcosis due to $C$. gattii species complex isolates were also reported in Europe, with VGI being the most prevalent molecular type (Hagen et al., 2012; Cogliati, 2013). In addition, some VGII isolates were the cause of infection in cases of cryptococcosis most probably acquired outside the continent (Hagen et al., 2010, 2012). In contrast, most infections due to VGI isolates were autochthonous (Hagen et al., 2012) as confirmed by recent European environmental surveys that showed the presence of VGI isolates in live trees and soil (Chowdhary et al., 2012; Colom et al., 2012; Linares et al., 2015; Cogliati et al., 2016a; Montagna et al., 2018). Monitoring the distribution of genotypes of $C$. neoformans and C. gatti species complexes in the European and Mediterranean environment is crucial to evaluate the evolution of this pathogen which seems capable to rapidly colonize new habitats. This is illustrated by a VGI and VGII outbreak, which was first detected in 1999 in Vancouver Island (Bartlett et al., 2012) and is now spreading along the Northern Pacific Coast of North America (Engelthaler et al., 2014). The outbreak is mainly due to variants of the VGII genotype (VGIIa, VGIIb, and VGIIc) that were likely imported from South America (Hagen et al., 2013; Billmyre et al., 2014; Engelthaler et al., 2014; Souto et al., 2016; Roe et al., 2018) and has adapted to the temperate climate of the Vancouver Bay (Mak et al., 2010). The ability of VGI and VGII isolates to potentially behave as primary pathogens infecting healthy patients has alarmed public health authorities.

A recent niche modeling study showed that Europe and the nonEuropean Mediterranean area (Northern Africa, Israel, Lebanon, Syria and Turkey) present optimal bioclimatic conditions for the survival in the environment of both $C$. neoformans and $C$. gattii species complexes with several areas where VNI, VNIV, and VGI can coexist (Cogliati et al., 2017). Therefore there is a potential risk for the emergence of new virulent genotypes or the establishment of virulent genotypes from other continents. In 2013 the Screen (Survey of CRyptococcosis through a European Epidemiological Network) Project, including about 200 European researchers, was created with the purpose of monitoring the epidemiology of Cryptococcus and cryptococcosis in Europe through data and isolate collection from clinical and veterinary cases as well as from environmental surveys (sites.google.com/view/screenprojectcryptococcus). The present study reports the first population genetic analysis carried out integrating all multi-locus sequence typing (MLST) data available for European isolates comparing the different genetic populations in both clinical and environmental isolates.

\section{Materials and methods}

\subsection{Isolates}

In the present study 476 isolates of $C$. neoformans and C. gattii species complexes from clinical $(n=275)$, veterinary $(n=16)$, and environmental $(n=185)$ sources were investigated. Isolates were from Italy $(n=159)$, France $(n=118)$, Germany $(n=96)$, Turkey $(n=41)$, Greece $(n=30)$, Spain $(n=16)$, Cyprus $(n=4)$, Denmark $(n=4)$, Belgium $(n=4)$, Libya $(n=3)$, and Portugal $(n=1)$ (Table 1$)$. Environmental isolates were recovered mainly from arboreal samples ( $n=176$ ), eight were from pigeon droppings and one from dust (Cogliati et al., 2016a, 2016b). Most of the isolates were mating type $\alpha$ and included 36 mating type a isolates (three VNI and 33 VNIV) (Table 1).

\subsection{MLST analysis}

All isolates were genotyped using the MLST scheme standardized by the "ISHAM Working Group for Genotyping of $C$. neoformans and $C$. gattii" (Meyer et al., 2009). Six housekeeping loci (CAP59, GPD1, LAC1, $P L B 1, S O D 1$, and URA5) and the IGS1 rDNA intergenic region were amplified and sequenced. Sequences were then compared with those present in the Cryptococcus MLST database (www.mycologylab.org) in order to assign an allele number. The combination of the seven-allele numbers of each isolate was also searched in the MLST database and a sequence type (ST) was assigned. Allele types and STs, which were not present in the MLST database, were sent to the curator of the database in order to assign a new allele or ST code. Most of the environmental isolates (176 isolates) were sequenced in the present study (Supplementary material, Table S1), whereas sequences of clinical isolates from Italy, France, Germany and data from Belgium and Denmark were obtained from previously reported results (Hagen et al., 2012; Cogliati et al., 2013; Danesi et al., 2014; Sanchini et al., 2014; Desnos-Ollivier et al., 2015; Cogliati et al., 2016b). The sequences of each allele type are available at the Cryptococcus MLST database and, furthermore, sequences of the new allele types were deposited in GenBank (www.ncbi. nlm.nih.gov). Accession numbers are reported in the Supplementary material, Table S1.

Supplementary data associated with this article can be found, in the online version, at https://doi.org/10.1016/j.fgb.2019.04.001.

\subsection{Phylogenetic analysis}

The concatenated sequences of the seven MLST loci of each isolate were aligned using Clustal Omega (www.ebi.ac.uk). The alignment file was then imported in MEGA software (www.megasoftware.com) for phylogenetic analysis. The maximum likelihood algorithm was used to infer a phylogenetic tree for both $C$. neoformans and $C$. gattii species complex isolates. Additional MLST sequence data from a set of VGI isolates of the $C$. gattii species complex previously reported in Europe were included in the phylogenetic analysis (Hagen et al., 2012). STs of European VGII and VGIII isolates were not included in the phylogenetic tree since they were already analyzed and discussed by Hagen et al.

Table 1

Geographical origin, source, and molecular type of the 476 C. neoformans and C. gattii species complex isolates investigated in the present study.

\begin{tabular}{|c|c|c|c|c|c|c|c|c|}
\hline & & \multicolumn{6}{|c|}{ Molecular types } & \multirow[t]{2}{*}{ Total } \\
\hline & & VNI & VNII & VNB & VNIV & VGI & VGIV & \\
\hline \multirow[t]{2}{*}{ Belgium } & $\mathrm{C}$ & & & & 2 & & & 2 \\
\hline & $\mathrm{E}$ & & & & 2 & & & 2 \\
\hline \multirow[t]{2}{*}{ Cyprus } & $\mathrm{C}$ & & & & & & & 0 \\
\hline & E & 4 & & & & & & 4 \\
\hline \multirow[t]{2}{*}{ Denmark } & $\mathrm{C}$ & & & & & & & 0 \\
\hline & $\mathrm{E}$ & & & & 4 & & & 4 \\
\hline \multirow[t]{2}{*}{ France } & $\mathrm{C}$ & 38 & 7 & & 70 & & & 115 \\
\hline & $\mathrm{E}$ & 3 & & & & & & 3 \\
\hline \multirow[t]{2}{*}{ Germany } & $\mathrm{C}$ & 77 & 1 & & 15 & & & 93 \\
\hline & $\mathrm{E}$ & & & & 3 & & & 3 \\
\hline \multirow[t]{2}{*}{ Greece } & $\mathrm{C}$ & & & & & & & 0 \\
\hline & $\mathrm{E}$ & 6 & & & 18 & 6 & & 30 \\
\hline \multirow[t]{2}{*}{ Italy } & $\mathrm{C}$ & 49 & 3 & 1 & 12 & & & 65 \\
\hline & E & 71 & & & 19 & 4 & & 94 \\
\hline \multirow[t]{2}{*}{ Libya } & $\mathrm{C}$ & & & & & & & 0 \\
\hline & $\mathrm{E}$ & 1 & 2 & & & & & 3 \\
\hline \multirow[t]{2}{*}{ Portugal } & $\mathrm{C}$ & & & & & & & 0 \\
\hline & $\mathrm{E}$ & 1 & & & & & & 1 \\
\hline \multirow[t]{2}{*}{ Spain } & $\mathrm{C}$ & & & & & & & 0 \\
\hline & E & 9 & & & 1 & 5 & 1 & 16 \\
\hline \multirow[t]{2}{*}{ Turkey } & $\mathrm{C}$ & & & & & & & 0 \\
\hline & $\mathrm{E}$ & 37 & & & 4 & & & 41 \\
\hline \multirow[t]{2}{*}{ Total } & C & 164 & 11 & 1 & 99 & 0 & 0 & 275 \\
\hline & $\mathrm{E}$ & 132 & 2 & 0 & 51 & 15 & 1 & 201 \\
\hline \multirow[t]{2}{*}{ Mating type } & $\alpha$ & 293 & 13 & 1 & 116 & 12 & 1 & 436 \\
\hline & $\mathbf{a}$ & 3 & 0 & 0 & 33 & 3 & 0 & 40 \\
\hline
\end{tabular}

$\mathrm{C}=$ Clinical isolates; $\mathrm{E}=$ Environmental isolates. 
(2012). Statistical analysis was performed by bootstrap analysis with 1000 replicates. The same alignment files were imported into Network 4 software (www.fluxus-engineering.com) to construct a medianjoining network for VNI and VNIV isolates. In addition, allele type and ST data were imported in Phyloviz software (www.philoviz.net) to construct a minimum spanning tree, using the goeBurst algorithm, for C. neoformans var. grubii, C. neoformans var. neoformans and the C. gattii species complex.

\subsection{Population genetics analysis}

To perform population genetics analysis isolates were stratified by different categories: by molecular type (VNI, VNII, VNIV), by source (clinical and environmental/veterinary, ENV), by molecular type and source (clinical VNI, ENV VNI, clinical VNIV, and ENV VNIV), and by country (France, Germany, Greece, Italy, Spain, and Turkey).

Intra- and inter-population genetic variability was estimated by several parameters: number of haplotypes (h), number of segregating sites (S), haplotype diversity (Hd), nucleotide diversity $(\pi)$, and average number of nucleotide differences (k). The neutrality tests Tajima's D, Fu \& Li's D, and Fu \& Li's F, were also calculated to verify if populations were at equilibrium or selection mechanisms were occurring. Minimum number of recombination events for each locus in each population was also estimated. In addition, number of fixed mutations, number of shared mutations, and the number of monomorphic mutations in one population and polymorphic in the other, were calculated to estimate genetic divergence between populations. Inter-population comparison of nucleotide diversity was also performed. Finally, a map showing the most probable routes of spreading of European genotypes was inferred comparing the VNI populations of the countries with a number of isolates $\geq 10$. Statistical analysis was performed calculating $F_{S T}$ index to verify genetic exchange between VNI populations of different countries. The genotypes which were present in more than one country, were shown in the map as well as the statistical support to justify the spreading from a country to another. All parameters and tests were calculated using DNAsp v5.10.1 software (www.ub.edu/dnasp). Linkage disequilibrium test between pairs of loci was performed by Arlequin software v3.0 (cmpg.unibe.ch/software/arlequin3) to evaluate the level of linkage between loci in a population.

\section{Results}

\subsection{Most of the STs are exclusive of Europe and ST23 is the most common}

MLST analysis identified 74 STs among C. neoformans var. neoformans (VNIV), 65 STs among C. neoformans var. grubii (56 VNI, 8 VNII, 1 VNB), and 5 STs amongst the $C$. gattii species complex (4 VGI and 1 VGIV) isolates. Whatever the origin, ST23 was the most common genotype $(22 \%)$ among the VNI isolates followed by ST63 $(10 \%)$, whereas the other STs showed a lower frequency $(0.3-7 \%)$ (Table 2). In contrast, among the VNIV isolates, a prevalent genotype was not identified, with the highest frequency observed for ST499 and ST160 (10\% and 8\%, respectively), followed by ST35 (7\%), ST116 (6\%), and ST112 (5\%). Most of the VNIV STs $(58 / 77,75 \%)$ were represented by only one isolate. ST160 and ST499 were the most frequent genotypes (20\% and $26 \%$, respectively) among VNIV ENV isolates, whereas among clinical isolates they showed only $3 \%$ and $0 \%$ frequency, respectively (Table 3 ). In addition, VNI isolates included nine STs that were present only among ENV isolates, and 37 STs were present only among clinical isolates. Amongst VNIV isolates 16 STs were exclusive to the ENV group, and 57 to the clinical group. Furthermore, comparing European STs results with those globally reported in the literature we found that $71 \%$ of VNI and $96 \%$ of VNIV STs analyzed in the present study were exclusive to Europe. Among the 13 VNII isolates eight STs were identified: ST40, ST41, ST42, ST43, ST96, ST106, ST107, and ST490. Finally, the 16 C. gattii species complex isolates analyzed in the present study were all from the environment, four isolates from Italy belonged to genotype ST156 (VGI) and ST197 (VGI), six from Spain to ST194 (VGI) and ST367 (VGIV), and six from Greece to ST204 (VGI).

\subsection{Most of VNI STs are included in a large clonal cluster}

Fig. 1A shows the four clonal clusters (CCs) identified by goeBurst algorithm among VNI isolates. The main cluster was CC23 including 30 STs and 98 isolates (50\%), followed by CC5 with 9 STs and 29 isolates (15\%), CC69 with 4 STs and 25 isolates (13\%), and CC75 with 3 STs and 16 isolates (8\%). The remaining 128 isolates representing 10 STs were not clustered.

Among VNIV isolates only four CCs were identified (Fig. 1B): CC135 including 5 STs and 14 isolates (9\%), CC160 with 3 STs and 14 isolates (9\%), CC499 including one ST and 16 isolates (10\%), and CC121 with 5 STs and 14 isolates (9\%). Seven CCs including 2 STs each were also identified, whereas others 49 STs were not clustered. In addition, the minimum spanning tree showed that $16 \%(9 / 56)$ of the STs in VNI isolates included both clinical and ENV isolates whereas only 5\% (4/77) were present in VNIV isolates ( $\mathrm{p}<0.05$ ) (Tables 2 and 3, Fig. $1 \mathrm{~A}$ and 1B).

With respect to the geographical origin, 11 VNI STs were represented by isolates from different countries, including ST63 distributed in six countries, ST58 in five countries, and ST5, ST23, and ST69 in four countries (Fig. 1A). On the contrary, among VNIV isolates only two STs (ST160 and ST135) were distributed in three different countries (Fig. 1B).

The 15 C. gattii VGI isolates clustered in two CCs: CC156 including isolates from Italy and Spain belonging to ST156, ST197, and ST194, and a second cluster including isolates from Greece, which all belonged to ST204 (Fig. 1C).

Table 2

Sequence type frequency among clinical and environmental VNI isolates.

\begin{tabular}{|c|c|c|c|}
\hline \multirow[t]{2}{*}{ Sequence type (ST) } & \multicolumn{3}{|c|}{ No. of isolates (\%) } \\
\hline & $\begin{array}{l}\text { Clinical } \\
(\mathrm{n}=164)\end{array}$ & $\begin{array}{l}\text { Environmental } \\
(\mathrm{n}=132)\end{array}$ & $\begin{array}{l}\text { Total } \\
(n=296)\end{array}$ \\
\hline 23 & 27 (16) & $40(31)$ & $67(22)$ \\
\hline 63 & $15(9)$ & $14(11)$ & $29(10)$ \\
\hline 69 & $19(11)$ & $1(0.8)$ & $20(7)$ \\
\hline 2 & $13(8)$ & $5(4)$ & $18(6)$ \\
\hline 5 & $15(9)$ & $3(2)$ & $18(6)$ \\
\hline 61 & $16(10)$ & $1(0.8)$ & $17(6)$ \\
\hline 264 & - & $16(12)$ & $16(5)$ \\
\hline 232 & - & $13(10)$ & $13(4)$ \\
\hline 32 & $10(6)$ & - & $10(3)$ \\
\hline 58 & $5(3)$ & $4(3)$ & $9(3)$ \\
\hline 68 & $2(1)$ & $3(2)$ & $5(2)$ \\
\hline 75 & $5(3)$ & - & $5(2)$ \\
\hline 46 & $4(2)$ & - & $4(1)$ \\
\hline 494 & - & $4(3)$ & $4(1)$ \\
\hline 544 & - & $3(2)$ & $3(1)$ \\
\hline 45,67 & $3(2)$ & - & $3(1)$ \\
\hline 56,289 & $2(1)$ & $1(0.8)$ & $3(1)$ \\
\hline $4,71,104,105$ & $2(1)$ & - & $2(0.7)$ \\
\hline $\begin{array}{c}226,341,493 \\
533,547\end{array}$ & - & $2(2)$ & $2(0.7)$ \\
\hline $\begin{array}{l}6,37,55,59,62 \\
64,65,70,72, \\
77, \\
81,84,138 \\
174,250, \\
288,290,488 \\
491,492, \\
495,545,546, \\
548,549, \\
550,551,552\end{array}$ & $1(0.6)$ & - & $1(0.3)$ \\
\hline
\end{tabular}

STs indicated in bold are exclusive of Europe. 
Table 3

Sequence type frequency among clinical and environmental VNIV isolates.

\begin{tabular}{|c|c|c|c|}
\hline \multirow[b]{2}{*}{ Sequence type (ST) } & \multicolumn{3}{|c|}{ No. of isolates (\%) } \\
\hline & $\begin{array}{l}\text { Clinical } \\
(\mathrm{n}=99)\end{array}$ & $\begin{array}{l}\text { Environmental } \\
(\mathrm{n}=51)\end{array}$ & Total $(n=150)$ \\
\hline 499 & - & $16(31)$ & $16(10)$ \\
\hline 160 & $3(3)$ & $9(18)$ & $12(8)$ \\
\hline 135 & $8(8)$ & $2(4)$ & $10(7)$ \\
\hline 116 & $9(9)$ & - & $9(6)$ \\
\hline 121 & $7(7)$ & - & $7(5)$ \\
\hline 112 & $4(4)$ & $2(4)$ & $6(4)$ \\
\hline 114,122 & $4(4)$ & - & $4(3)$ \\
\hline 553 & - & $4(9)$ & $4(3)$ \\
\hline 180 & $2(2)$ & $1(2)$ & $3(2)$ \\
\hline $110,125,168$ & $3(3)$ & - & $3(2)$ \\
\hline 294 & - & $2(4)$ & $2(1)$ \\
\hline $133,134,165,508$ & $2(2)$ & - & $2(1)$ \\
\hline $\begin{array}{l}251,252,496,498 \\
500, \\
517,522,523 \\
524,554\end{array}$ & - & $1(2)$ & $1(0.7)$ \\
\hline $\begin{array}{l}108,111,118,119, \\
120, \\
123,124,128, \\
129,130, \\
131,132,136, \\
154,155, \\
156,157,158, \\
159,161, \\
162,163,164, \\
166,167, \\
170,178,179 \\
181,279, \\
486,487,505, \\
506,507, \\
509,510,512, \\
514,515, \\
516,518,519 \\
520,530, \\
531\end{array}$ & $1(1)$ & - & $1(0.7)$ \\
\hline
\end{tabular}

STs indicated in bold are exclusive of Europe.

3.3. Some STs do not fit in the four major clusters VNI, VNII, VNB, and VNIV

Maximum likelihood phylogenetic reconstruction, performed including the 139 STs of the $C$. neoformans species complex of the present study, identified four major molecular types VNI, VNII, VNB, and VNIV, which were supported by more than $90 \%$ of trees produced by bootstrap analysis. However, some STs presented an ambiguous topology either among VNIV (ST496, ST506, ST507, ST508, ST516 and ST520), VNI (ST232, and ST488) or VNII (ST42 and ST107) (Fig. 2).

When the four VGI STs identified in the present study were compared to those previously reported in Europe, they were grouped in a large cluster including STs mostly present exclusively in Europe. In this group only ST56 and ST58 included isolates from other continents. Isolates belonging to ST225, ST232, and ST57 belonged to other clusters and were probably imported from other continents. The VGIV isolate belonging to ST367 was unique and was different from any other global isolate so far reported (Fig. 3).

Network analysis showed that the VNII group of isolates is not a homogenous group but includes genotypes with high genetic diversity that has some genetic relationship both with VNI and VNB groups (Fig. 4). In addition, comparison of network reconstruction performed for VNI and VNIV isolates showed the different genetic evolution of these two groups. VNI isolates displayed numerous large clonal clusters and few dispersed genotypes, in contrast VNIV isolates showed a high number of dispersed genotypes and few small CCs (Fig. 4).

\subsection{High Hd in both VNI and VNIV groups of isolates}

Table 4 shows the genetic indexes calculated for the different group of isolates investigated in the present study. Comparison of VNI, VNII, and VNIV isolates showed that VNIV and VNI have the highest Hd values which was lower in VNII isolates. In contrast, the $\pi$ value in VNII isolates was higher than that found in VNI with a $\mathrm{k}$ of 12.4 versus 8.6, respectively. Neutrality test carried out with three different algorithms showed that only VNIV isolates are under selective pressure. Independent analysis of each of the seven MLST loci showed that there was no polymorphism of $L A C 1$ in VNII isolates, and a low Hd was also observed for the GPD1 locus in VNIV and the SOD1 locus in VNI isolates. The IGS1 locus was the most variable in the three group of isolates with VNIV showing the highest value followed by VNII and VNI (Supplementary material Fig. S1A). When the $C$. neoformans species complex isolates were grouped in two categories, clinical and ENV isolates, no differences in $\mathrm{Hd}, \pi$, and neutrality test were found. A similar result was confirmed by single loci analysis, except for the GPD1 locus, which showed a low $\mathrm{Hd}$ in the ENV isolates (Supplementary material Fig. S1B). Stratification of VNI and VNIV by clinical and ENV isolates revealed differences in genetic parameters. The group including clinical VNIV isolates showed the highest Hd, whereas the lowest value was observed in the group including ENV VNI isolates. The other two categories (clinical VNI and ENV VNIV) had a similar Hd intermediate value. A high $\pi$ value (0.01048) was observed in ENV VNIV isolates, but lower values were calculated for ENV VNI and clinical VNIV isolates, and a very low value $(0.00195)$ was found for the clinical VNI group. Neutrality tests showed that selective pressure is occurring in all groups of isolates except the clinical VNI group. Differences in Hd were also observed analyzing single loci (Supplementary material Fig. S1C). The GDP1 locus showed a very low Hd values in the ENV VNI group compared to the other ones. The greatest inter-population difference in Hd values was found for the IGS1 locus with the two VNIV group of isolates (clinical and ENV) showing a value ranging from 0.7 to 0.8 and VNI isolates showing a value lower than 0.3 . A similar difference, but to a minor extent, was observed in the URA5 locus where the calculated values were 0.8 for the VNI groups and $0.4-0.6$ for VNIV. In both CAP59 and SOD1 loci Hd values were decreasing in the following order: ENV VNIV > clinical VNIV > ENV VNI > clinical VNI. In contrast, all groups showed a similar Hd in LAC1 and PLB1 loci.

Stratification of isolates by country revealed that isolates from France had the highest $\mathrm{Hd}$ and $\pi$ values, whereas those from Greece had the lowest $\mathrm{Hd}$ value but a high $\pi$ value. The other groups analyzed (Italy, Germany, Spain, and Turkey) showed similar Hd and $\pi$ values ranging from 0.84 to 0.95 and from 0.026 to 0.041 , respectively. Selective pressure was observed in Italy, France, Turkey, and Spain but not in Germany and Greece.

\subsection{Linkage disequilibrium of PLB1 in VNI isolates and LAC1 in clinical VNIV isolates}

Linkage disequilibrium test between pairs of loci performed for the VNI, VNII, and VNIV isolates, showed that in both VNI and VNIV isolates most of loci were linked, but some differences were observed. In the VNI group the PLB1 locus was linked to each of the other loci, whereas this was not true in the VNIV group. By contrast the LAC1 and SOD1 loci showed a high percentage of linkage in VNIV isolates, but not in the VNI group. Pairwise comparison of loci in VNII isolates revealed that most of the loci were not linked to each other (Fig. 5).

Stratified analysis by clinical and ENV of VNI isolates revealed that linkage disequilibrium pattern of the ENV group was identical to that of the whole VNI group of isolates, in contrast the clinical VNI group showed mostly non-linked loci, except for PLB1. Amongst VNIV isolates, the clinical and ENV groups showed a difference in the LAC1 linkage pattern, which was only present in the former group of isolates but not in the latter one (Fig. 5). 


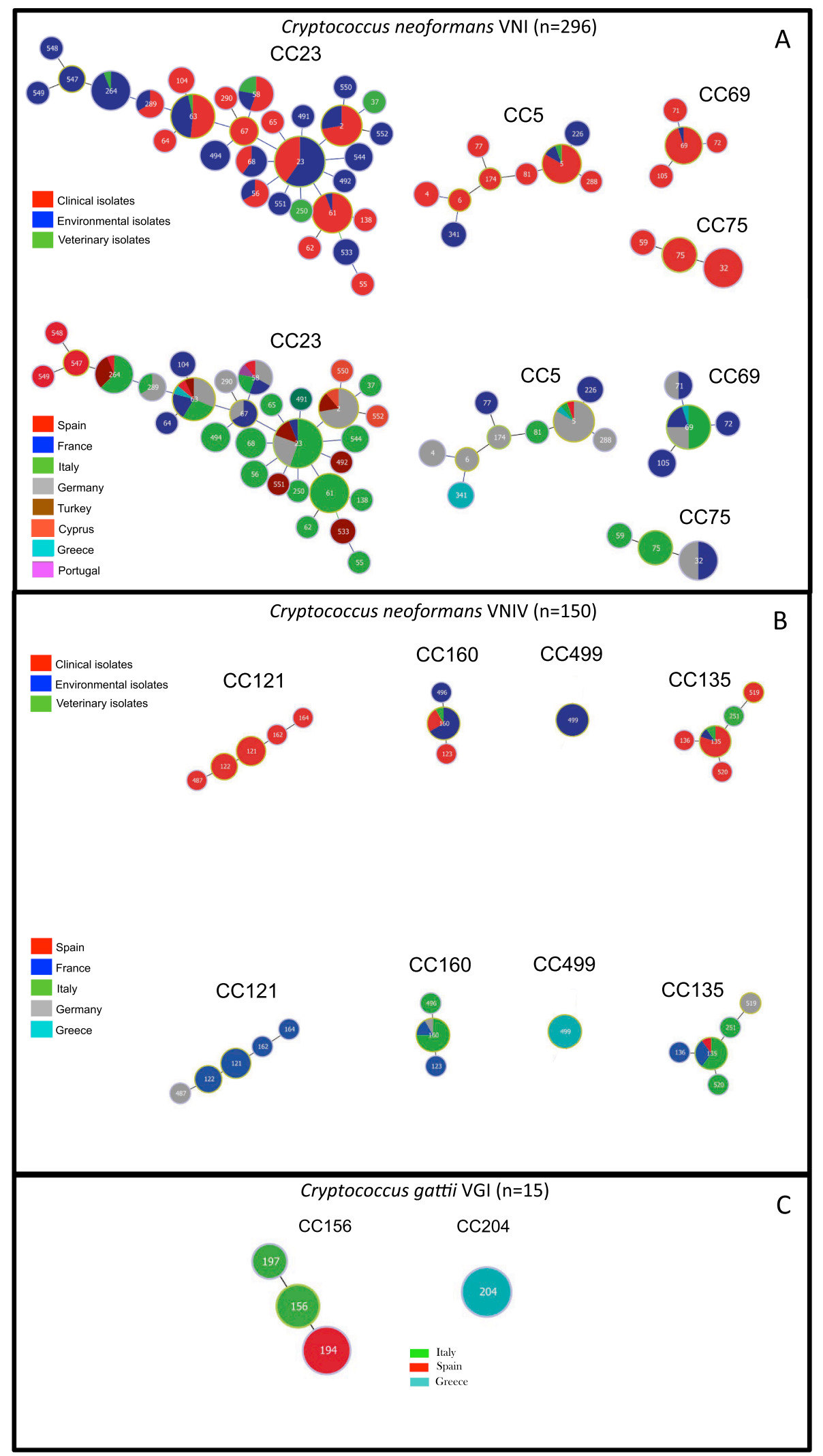

Fig. 1. Minimum spanning tree showing the main clonal clusters (CC) linked by a single locus difference. Isolates have been identified according to the source and the country of isolation. Each circle represents a unique sequence type (ST), and the circle size is proportional to the number of isolates within each ST. 


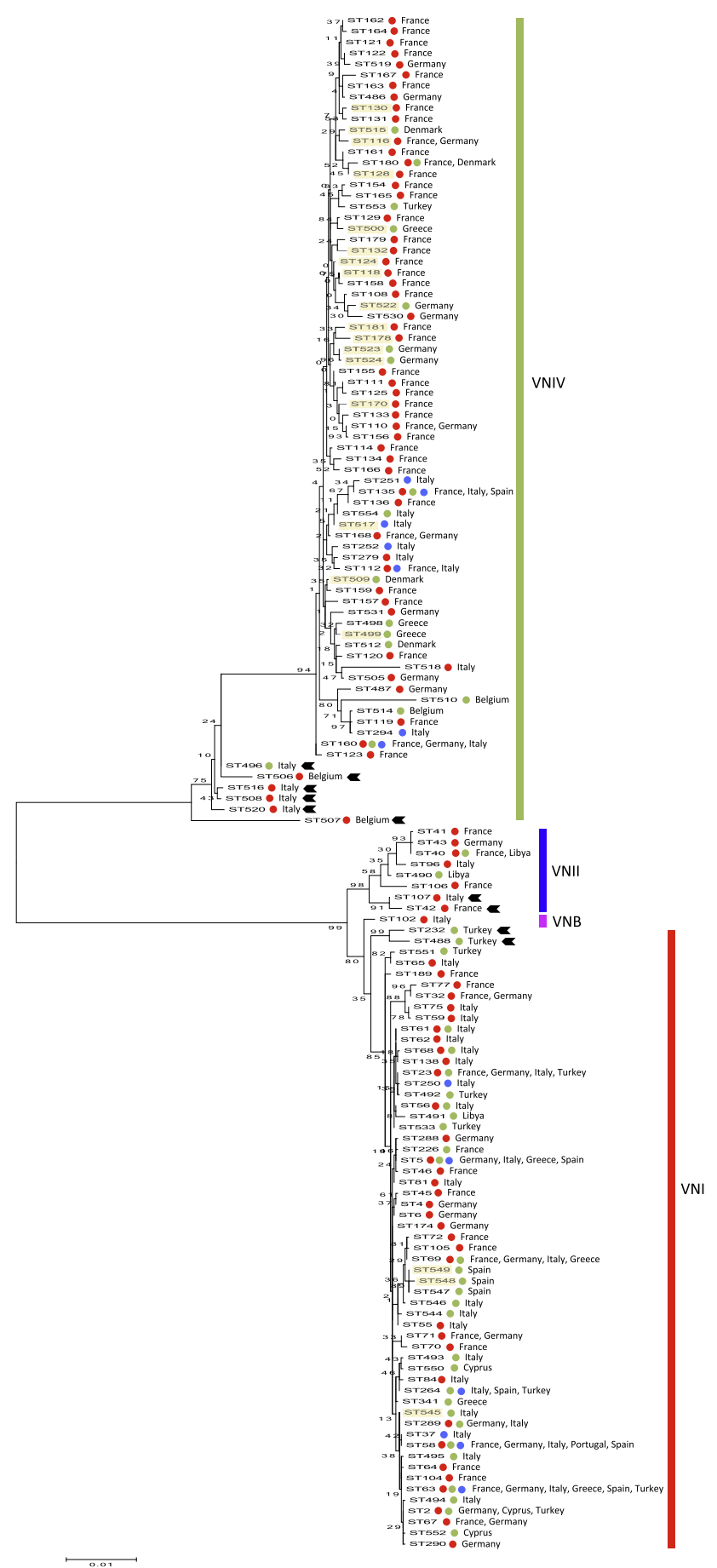

Fig. 2. Maximum likelihood phylogenetic tree inferred using the concatenated sequences of the seven MLST loci (CAP59, GPD1, LAC1, PLB1, SOD1, URA5, and the IGS1 region) of the Cryptococcus neoformans species complex sequence types (ST) investigated in the present study. Bootstrap values, based on 1000 replicates, are reported at each branch node. Red dots indicate STs including clinical isolates, green dots environmental isolates, and blue dots veterinary isolates. STs highlighted in light yellow include mating type a isolates. Black arrows indicate STs with an ambiguous topology. (For interpretation of the references to colour in this figure legend, the reader is referred to the web version of this article.)

\subsection{Environmental isolates are the most recombinants in both VNI and VNIV groups}

The minimum number of recombination events, calculated for each group of isolates, is reported in Table 5. Recombination was observed in

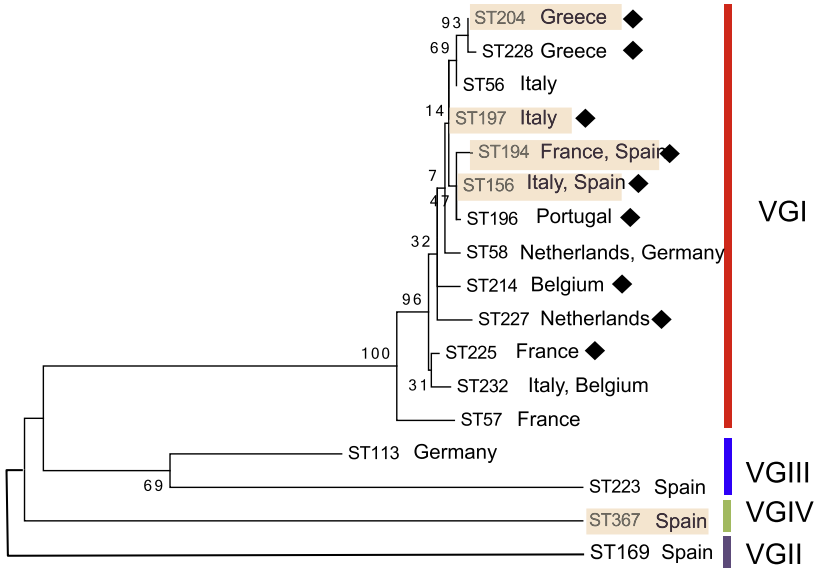

Fig. 3. Maximum likelihood phylogenetic tree inferred using the concatenated sequences of the seven MLST loci (CAP59, GPD1, LAC1, PLB1, SOD1, URA5, and the IGS1 region) of the Cryptococcus gattii species complex sequence types (ST) investigated in the present study (marked in light red). STs are compared with STs from European VGI isolates previously reported by other authors (Hagen et al., 2010) who analyzed also further VGII and VGIII isolates not included in the current analysis. Bootstrap values, based on 1000 replicates, are reported at each branch node. Black squares indicate European autochthonous STs. (For interpretation of the references to colour in this figure legend, the reader is referred to the web version of this article.)

VNIV isolates but not in VNI and VNII groups. The LAC1 locus was the most recombinant one whereas no recombination events were found in the PLB1 locus. Comparison of clinical and ENV isolates showed recombination in both groups with the LAC1 locus having 21 recombination events in the ENV group versus 7 in the clinical one. Both clinical and ENV VNIV isolates had recombination at all loci except $P L B 1$, whereas in the VNI isolates only the ENV group showed three recombinant loci (LAC1, PLB1, and SOD1). Finally, recombination events were observed in all countries, except in Spain.

\subsection{Comparison of environmental VNI and VNIV isolates showed a high rate of shared mutations and no fixed mutations}

The first row of graphics in Fig. 6 shows the comparison between VNI, VNII, and VNIV isolates. VNIV versus VNI and VNII showed a high percentage of fixed mutations and a low percentage of shared mutations confirming the genetic distance between these group of isolates. Furthermore, in both comparisons VNIV showed the highest percentage of polymorphic sites compared to the other two group of isolates. Genetic comparison between VNI and VNII showed a lower percentage of fixed mutations and a higher percentage of shared mutations compared to the previous two analyses, and that VNI was more polymorphic than VNII isolates. Comparing clinical versus ENV VNI isolates, and clinical versus ENV VNIV isolates, ENV isolates were more polymorphic than clinical ones, especially ENV VNI isolates, and no fixed mutations were observed. The last two comparisons showed the most interesting results. VNI versus VNIV clinical groups presented a high percentage of fixed mutations and a lower percentage of shared mutations as expected, with clinical VNIV being more polymorphic than VNI. On the contrary, comparisons between ENV isolates surprisingly did not present any fixed mutations and a high percentage of shared mutations, with VNI being more polymorphic than VNIV.

Inter-population comparison of nucleotide diversity is shown in Fig. 7. Clinical and ENV isolates presented an overlapping nucleotide diversity curve ( $\mathrm{k}=196$ versus 173 , respectively) (Fig. 7A and Table 4). 


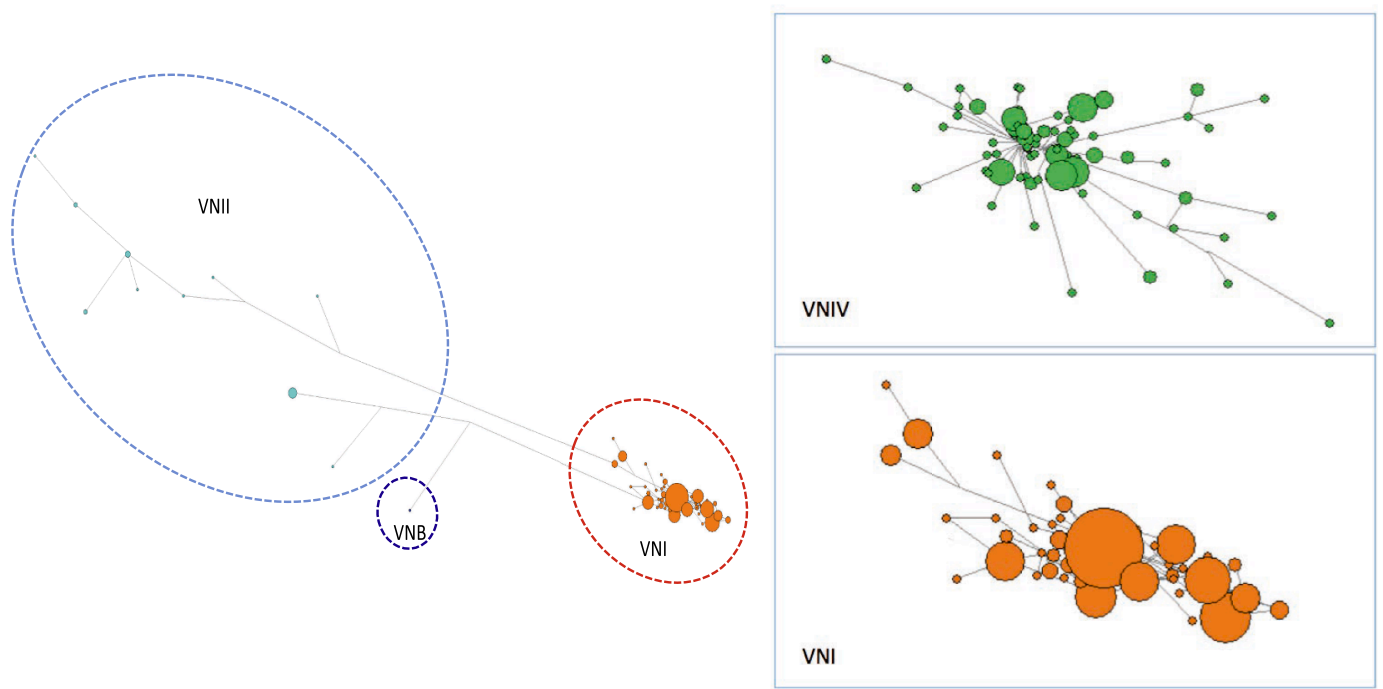

Fig. 4. Network analysis showing genetic relationships between VNI, VNII and VNB isolates (right-side panel) and between VNI and VNIV isolates (left-side panels). Each circle represents a sequence type, the size of the circles is proportional to the numbers of isolates, and the length of each branch is proportional to genetic distance.

Table 4

Parameters values of population genetics calculated for the populations investigated in the present study.

\begin{tabular}{|c|c|c|c|c|c|c|c|c|c|}
\hline Population (no. of isolates) & $\begin{array}{l}\text { Polymorphic } \\
\text { sites (S) }\end{array}$ & $\begin{array}{l}\text { No. of } \\
\text { mutations } \\
\text { (Eta) }\end{array}$ & $\begin{array}{l}\text { No. of } \\
\text { haplotypes }\end{array}$ & $\begin{array}{l}\text { Haplotype } \\
\text { diversity (Hd) }\end{array}$ & $\begin{array}{l}\text { Average no. of } \\
\text { nucleotide } \\
\text { difference }(\mathrm{K})\end{array}$ & $\begin{array}{l}\text { Nucleotide } \\
\text { diversity }(\pi)\end{array}$ & TajimaD & FuLiD & FuLiF \\
\hline VNI $(n=296)$ & 102 & 102 & 54 & 0.917 & 8.67526 & 0.00264 & -1.0652 & -1.6819 & -1.6536 \\
\hline VNII $(n=13)$ & 43 & 43 & 8 & 0.897 & 12.41026 & 0.0037 & 0.3017 & 0.7634 & 0.7318 \\
\hline VNIV $(n=150)$ & 386 & 420 & 76 & 0.975 & 20.87302 & 0.00615 & $-2.3134^{* *}$ & $-6.8658^{* * *}$ & $-5.6255^{* *}$ \\
\hline CLINICAL $(\mathrm{n}=275)$ & 640 & 675 & 99 & 0.969 & 195.99388 & 0.05824 & $3.3209^{* k t}$ & 0.2625 & $2.2016^{k * \hbar}$ \\
\hline ENVIRONMENTAL $(\mathrm{n}=185)$ & 602 & 642 & 55 & 0.921 & 172.85493 & 0.05015 & $1.9673^{*}$ & 0.5456 & $1.4837^{*}$ \\
\hline VNI CLINICAL $(\mathrm{n}=164)$ & 43 & 43 & 31 & 0.919 & 6.21739 & 0.00195 & 0.0795 & -0.3883 & -0.2285 \\
\hline VNI ENVIRONMENTAL $(\mathrm{n}=132)$ & 492 & 499 & 29 & 0.859 & 23.72921 & 0.00697 & $-2.3989^{k * k}$ & $2.4411^{k * k}$ & 0.2253 \\
\hline VNIV CLINICAL $(\mathrm{n}=99)$ & 254 & 266 & 55 & 0.977 & 17.00417 & 0.00723 & -1.5402 & -3.0985 & $-2.9078^{*}$ \\
\hline VNIV ENVIRONMENTAL $(\mathrm{n}=51)$ & 415 & 450 & 25 & 0.909 & 24.39592 & 0.01048 & $-2.166^{*}$ & $-3.7735^{k *}$ & $-3.7839^{* *}$ \\
\hline FRANCE $(\mathrm{n}=118)$ & 562 & 583 & 63 & 0.984 & 206.30268 & 0.06193 & $3.9762^{k / k k \pi}$ & $2.2139^{k * k}$ & $3.6125^{* \star *}$ \\
\hline GERMANY $(\mathrm{n}=96)$ & 557 & 574 & 26 & 0.901 & 136.09888 & 0.04178 & 1.5002 & 1.3588 & $1.7042^{*}$ \\
\hline GREECE $(n=24)$ & 544 & 569 & 11 & 0.770 & 187.37 & 0.05496 & 1.2337 & 0.8888 & 1.1779 \\
\hline ITALY (n = 155) & 556 & 578 & 43 & 0.928 & 134.18172 & 0.03963 & 1.5467 & $2.0203^{k * \hbar}$ & $2.1465^{* *}$ \\
\hline SPAIN $(\mathrm{n}=10)$ & 491 & 493 & 8 & 0.956 & 85.53333 & 0.02593 & $-2.0918^{k * k}$ & $-2.4981^{k * k}$ & $-2.7097^{* *}$ \\
\hline TURKEY $(\mathrm{n}=41)$ & 538 & 552 & 11 & 0.840 & 103.38902 & 0.03157 & -0.1907 & $1.6077^{* * \hbar}$ & 1.1366 \\
\hline
\end{tabular}

$$
\begin{aligned}
& * \mathrm{p}<0.05 . \\
& * * \mathrm{p}<0.01 \\
& * * * \mathrm{p}<0.001
\end{aligned}
$$

When these two group of isolates were compared by considering only VNI isolates, the difference became evident $(\mathrm{k}=6$ versus 24 , respectively) with clinical isolates presenting a lower nucleotide diversity in most of the loci, except $L A C 1$ and PLB1, compared to ENV ones (Fig. 7B and Table 4). On the contrary, the nucleotide diversity in VNIV isolates was similar $(\mathrm{k}=17$ in clinical isolates versus 24 in environmental ones, Table 4) with low values of clinical VNIV only for LAC1 and SOD1 loci (Fig. 7C).

Fig. 7D shows a great difference in nucleotide diversity comparing VNI versus VNIV isolates ( $\mathrm{k}=9$ and 21, respectively). This difference was not so evident when the two group of isolates $(\mathrm{k}=23$ in VNI and $\mathrm{k}=24$ in VNIV) where compared in the ENV group (Fig. 7E and Table 4). In the clinical group nucleotide diversity was very low in both group of isolates ( $\mathrm{k}=6 \mathrm{in}$ VNI and $\mathrm{k}=17$ in VNIV) with the exception of higher values for GPD1 and IGS1 loci in the VNIV group (Fig. 7F and Table 4).

\subsection{Genetic flow analysis supports the spreading in Europe of the most} common VNI STs

Results of genetic flow analysis showed that, in Europe, the main genetic flows, which are supported by $F_{S T}$ statistics, were identified between Italy, Germany, Spain, and Turkey. Analyzing the most frequent STs in Europe, that is ST23, ST63, and ST69, and ST5, all belonging to the VNI molecular type, it was possible to infer the main routes of spreading across the continent (Fig. 8). ST23 was found in Italy, Germany, Turkey and France with a spreading direction South to North or vice versa. ST63 was the most spreading genotype, presenting an additional directional component towards or from Western Europe. ST69 was primarily confined in central Europe with main genetic flows between Italy and Germany. ST5 spreads mainly from Germany towards Southern and Western Europe. 

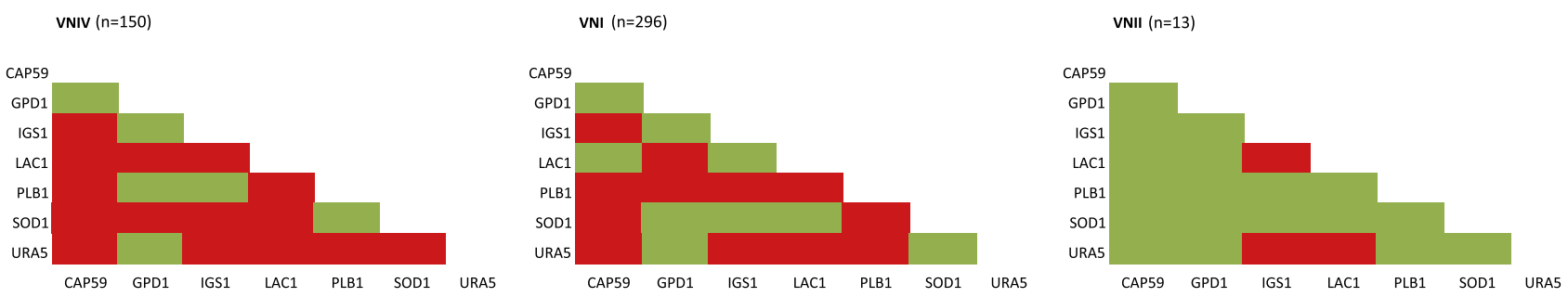

CLINICAL VNIV ( $n=99)$

CLINICAL VNI $(n=164)$
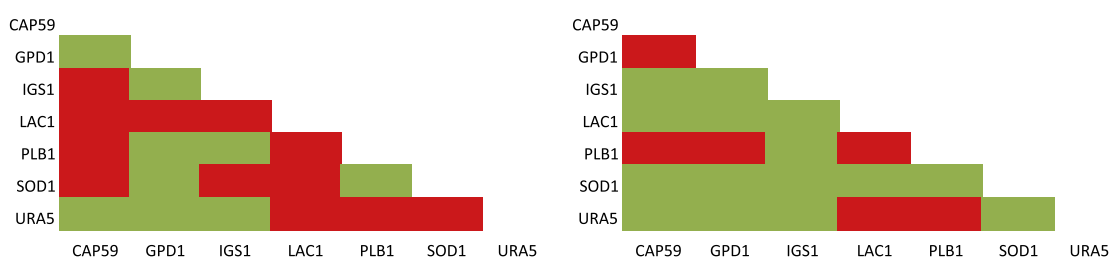

No linkage

ENVIRONMENTAL VNIV $(n=51)$

ENVIRONMENTAL VNI $(n=132)$
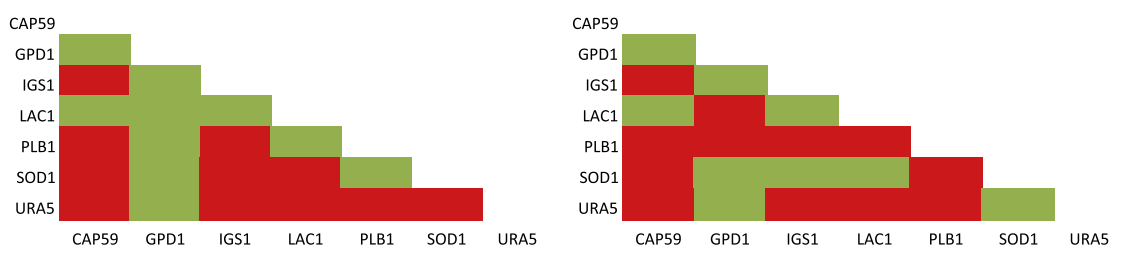

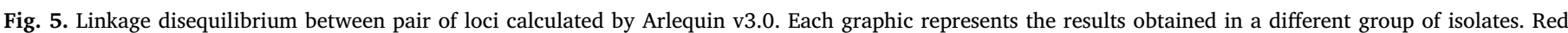

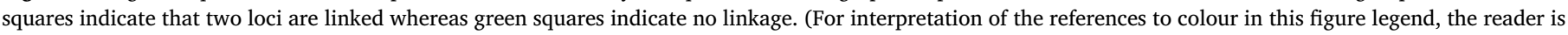
referred to the web version of this article.)

Table 5

Minimun number of recombination events calculated among populations investigated in the present study.

\begin{tabular}{|c|c|c|c|c|c|c|c|c|}
\hline Population & CAP59 & GPD1 & IGS1 & $L A C 1$ & PLB1 & SOD1 & URA5 & Total \\
\hline VNI $(n=296)$ & 0 & 0 & 0 & 0 & 0 & 0 & 0 & 0 \\
\hline VNII $(n=13)$ & 0 & 0 & 0 & 0 & 0 & 0 & 0 & 0 \\
\hline $\operatorname{VNIV}(\mathrm{n}=150)$ & 4 & 2 & 6 & 17 & 0 & 3 & 5 & 37 \\
\hline CLINICAL $(\mathrm{n}=275)$ & 5 & 3 & 9 & 7 & 1 & 3 & 5 & 33 \\
\hline ENVIRONMENTAL $(\mathrm{n}=185)$ & 4 & 2 & 5 & 21 & 1 & 4 & 3 & 40 \\
\hline VNI CLINICAL ( $\mathrm{n}=164)$ & 0 & 0 & 0 & 0 & 0 & 0 & 0 & 0 \\
\hline VNI ENVIRONMENTAL $(\mathrm{n}=132)$ & 0 & 0 & 0 & 1 & 1 & 3 & 0 & 5 \\
\hline VNIV CLINICAL (n = 99) & 4 & 0 & 5 & 1 & 0 & 3 & 5 & 18 \\
\hline VNIV ENVIRONMENTAL $(\mathrm{n}=51)$ & 2 & 12 & 5 & 11 & 0 & 1 & 2 & 28 \\
\hline FRANCE $(\mathrm{n}=118)$ & 3 & 3 & 6 & 2 & 1 & 2 & 3 & 20 \\
\hline GERMANY $(\mathrm{n}=96)$ & 2 & 2 & 1 & 3 & 0 & 1 & 2 & 11 \\
\hline GREECE $(\mathrm{n}=24)$ & 0 & 2 & 4 & 9 & 0 & 0 & 0 & 15 \\
\hline ITALY $(\mathrm{n}=155)$ & 2 & 3 & 6 & 1 & 1 & 3 & 2 & 18 \\
\hline SPAIN $(\mathrm{n}=10)$ & 0 & 0 & 0 & 0 & 0 & 0 & 0 & 0 \\
\hline TURKEY $(\mathrm{n}=41)$ & 0 & 1 & 2 & 3 & 1 & 2 & 0 & 9 \\
\hline
\end{tabular}

\section{Discussion}

The present study is the largest genetic population analysis carried out in Europe and the Mediterranean area integrating most of the available MLST datasets from clinical and environmental isolates reported in this geographical region. The analyzed collection of isolates included mainly isolates belonging to the $C$. neoformans species complex (VNI, VNII, VNIV and one VNB) and a few environmental C. gattii species complex isolates.

The results reported above show a high genetic diversity among the C. neoformans species complex isolates here investigated, confirming previous MLST studies carried out on clinical isolates in Italy, France, and Germany (Cogliati et al., 2013; Sanchini et al., 2014; DesnosOllivier et al., 2015). The high haplotype diversity of VNI isolates is comparable to those calculated for other continents but higher than that observed in Asia (Khayhan et al., 2013; Ferreira-Paim et al., 2017). However, the present study includes more isolates from both clinical and environmental sources. In addition, a large number of clinical and environmental VNIV isolates were included in this study providing new insights about genetic differences and relationships with VNI isolates.

Our results show a major clonal cluster (CC23) being present in Europe including 50\% of all VNI isolates with ST23 and ST63 being the most frequent genotypes. By contrast, fewer and smaller CCs are present amongst VNIV isolates with no prevalent genotypes. Interestingly, most of the VNI and VNIV STs (71\% and 96\%, respectively) seem unique to Europe and absent in other continents suggesting that these genotypes are not yet spreading outside the continent. On the other hand, some VNI STs belonging to CC5, CC69, and CC75 seem to be 

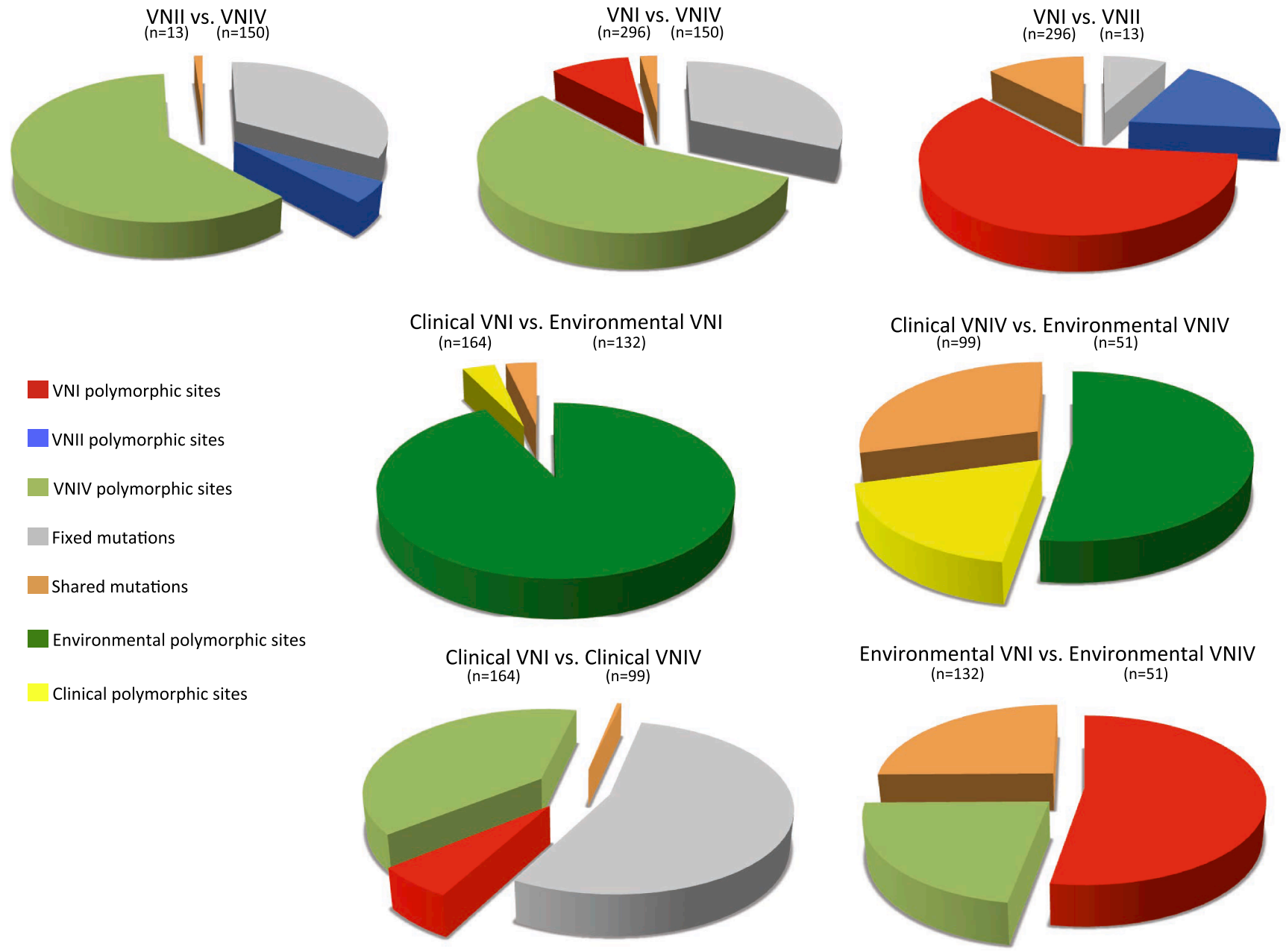

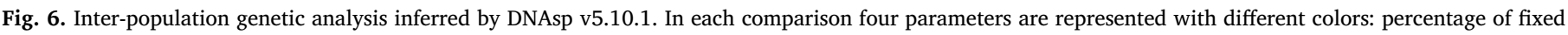

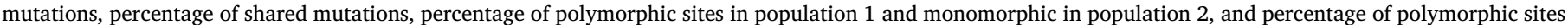
in population 2 and monomorphic in population 1 .

imported from other continents and are now spreading in Europe throughout Germany, France, and Italy.

Phylogenetic analysis showed that isolates from Europe and the Mediterranean area belonging to the $C$. neoformans species complex are grouped in four clusters corresponding to the molecular types VNI, VNII, VNB, and VNIV, and revealed some isolates that showed an unexpected branch topology suggesting that their genome contains genetic remains of ancestral groups of the $C$. neoformans species complex. These findings are supported by other studies which reported these kind of isolates (Cogliati et al., 2016b; Rhodes et al., 2017; Muñoz et al., 2018,). Further investigation of these isolates is needed to clarify their origin.

Network analysis, supported by haplotype diversity and recombination events values, confirmed the different genetic population structure of VNI and VNIV isolates, the former presenting a primarily clonal structure and the latter a recombinant structure. The same conclusions are reported by previous studies carried out with French clinical isolates and in a number of global VNIV isolates (DesnosOllivier et al., 2015; Cogliati et al., 2016b). In the present study genetic features of clinical and environmental isolates were compared for the first time providing new insights about genetic relationships and differences between VNI and VNIV isolates. The obtained results show that VNIV isolates present a higher genetic diversity compared to VNI, and that VNI and VNIV environmental isolates show a higher genetic diversity compared to their respective clinical isolates. These results suggest that in Europe VNIV strains has found favorable environmental conditions and have increased their genetic diversity most likely thanks to sexual recombination due to the presence of both mating type a and $\alpha$ in the environment (Cogliati et al., 2013, 2016a). In addition, recent studies showed that VNIV strains have a higher probability to be recovered in the areas of Europe characterized by a sub-continental climate due to tolerance of lower temperatures than VNI (Cogliati et al., 2017). Similarly, the higher genetic diversity of ENV VNI compared to clinical VNI could be explained with a residual ability of environmental isolates to sexually recombine. This is confirmed by the analysis of recombination events which were identified only in the environmental VNI isolates. In addition, the presence of VNI mating type a and mating type $\alpha$ isolates in the European environment and their ability to mate were shown previously (Cogliati et al., 2016a).

Interesting conclusions were drawn by the analysis of linkage disequilibrium results and nucleotide diversity indexes comparing ENV and clinical groups in VNI and VNIV isolates. In the clinical VNIV isolates, the LAC1 locus presents a full linkage with all other loci but this was not observed in ENV VNIV isolates. This means that only some alleles of the LAC1 locus are represented amongst the clinical isolates, probably due to selective pressure. On the contrary, in ENV isolates, the LAC1 locus presents a higher variability of combinations that could be explained by the necessity of the fungus to adapt to a wide range of substrates to which it is exposed in the environment. Nucleotide diversity values of the $L A C 1$ locus also support this hypothesis as $\pi$ values of clinical VNIV are lower than those observed in ENV VNIV isolates. A recent study on the LAC1 gene in a set of VNIV strains confirms these 


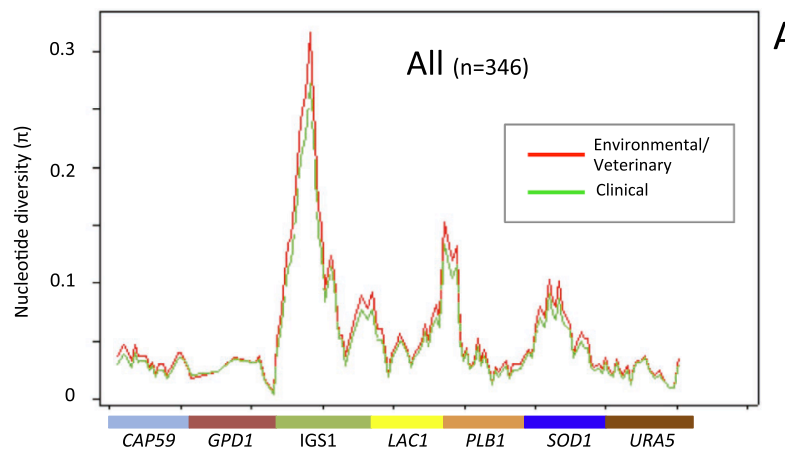

A
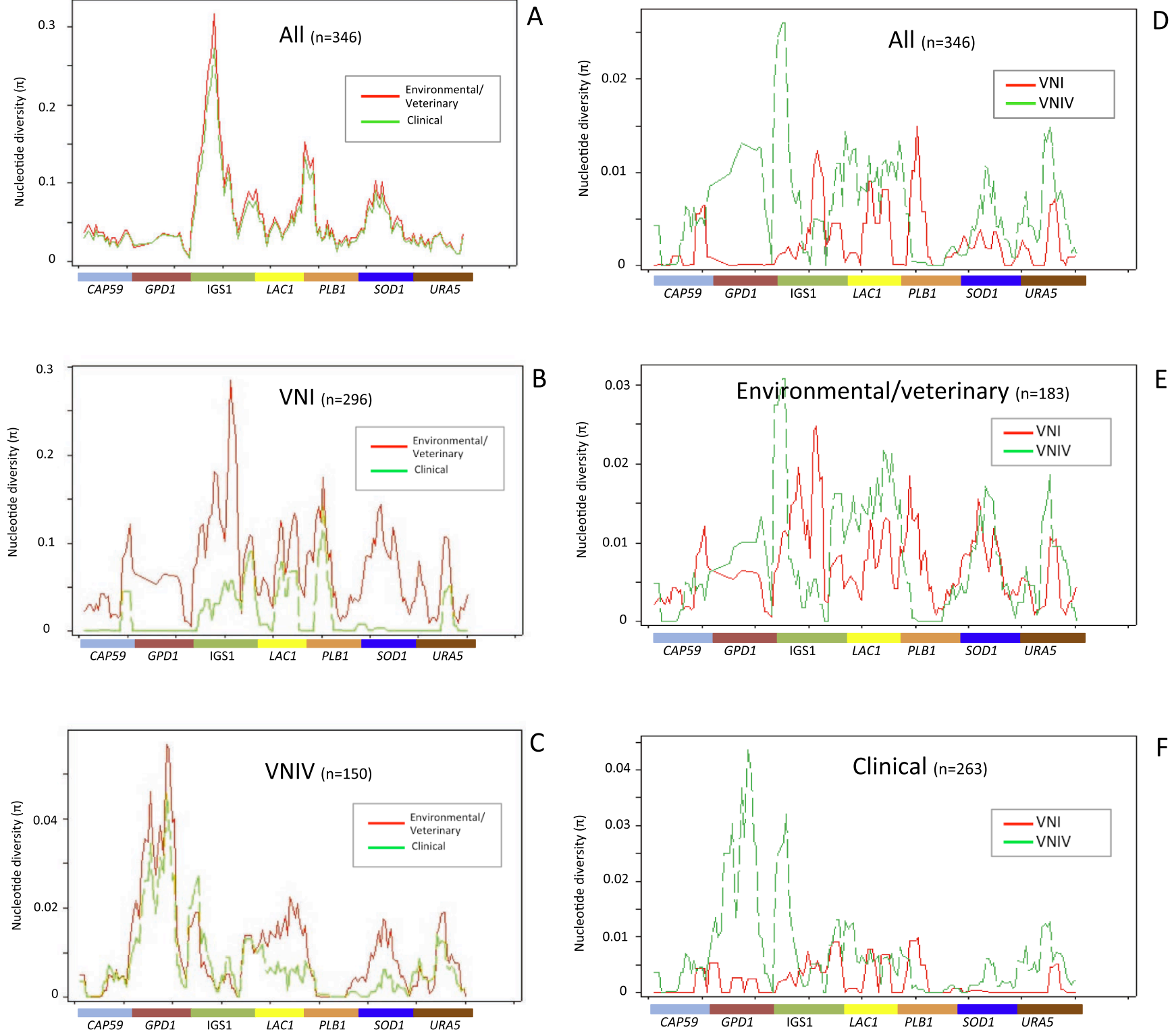

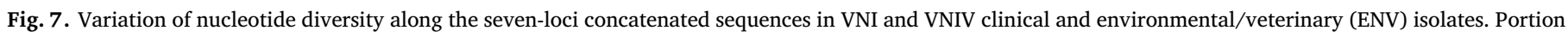

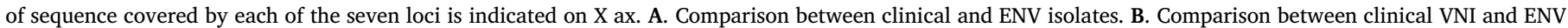

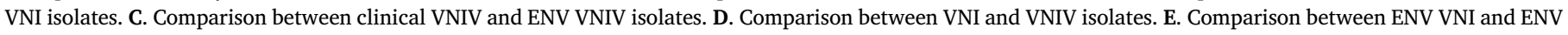
VNIV isolates. F. Comparison between clinical VNI and clinical VNIV isolates.

results, reporting an association between specific sequence polymorphisms in the LAC1 gene and the level of melanin production (Samarasinghe et al., 2018).

Linkage disequilibrium and nucleotide diversity analyses of VNI isolates identified a significant difference between the clinical and ENV groups. Clinical isolates do not show linkage between any locus, except for the PLB1 locus, whereas most of the loci in ENV isolates, including the PLB1 locus, are linked. Therefore, in both group of isolates, the $P L B 1$ locus showed a high level of linkage suggesting that evolution has selected a restricted set of PLB1 alleles that have been conserved amongst the environmental isolates and that could play an important role in the parasitic phase of the fungal life cycle. Furthermore, the absence of linkage between the other loci observed in clinical VNI isolates suggests that a multitude of genotype combinations are able to cause infection conversely to what is observed in clinical VNIV isolates where linkage between loci limits the possible combinations. This is also supported by the significant difference observed between VNI and VNIV in the percentage of STs containing both clinical and environmental isolates ( $16 \%$ versus $5 \%$, respectively). These genetic differences between VNI and VNIV isolates could be the basis of their different ability to cause infections, with VNI being the most prevalent molecular type causing cryptococcosis globally (Cogliati, 2013). Interpopulation comparisons revealed that the major source of polymorphism is the environment for both VNI and VNIV isolates, having $93 \%$ and $53 \%$ of polymorphic sites, respectively, observed in ENV isolates. This suggests that environmental stress is more effective to generate new genotypes than host condition stress. Our results also showed that, although clinical VNI and clinical VNIV isolates are genetically divergent with $54 \%$ fixed mutations, no fixed mutation has been observed by comparing environmental isolates of VNI and VNIV which presented $25 \%$ shared mutations. Therefore, ENV VNI and VNIV isolates are less genetically divergent than clinical ones. At present, genetic population studies on $C$. neoformans species complex reporting a high genetic divergence between VNI and VNIV isolates are mostly based on clinical isolates, taking in scarce consideration of environmental isolates. By contrast, the present study carried out a more 

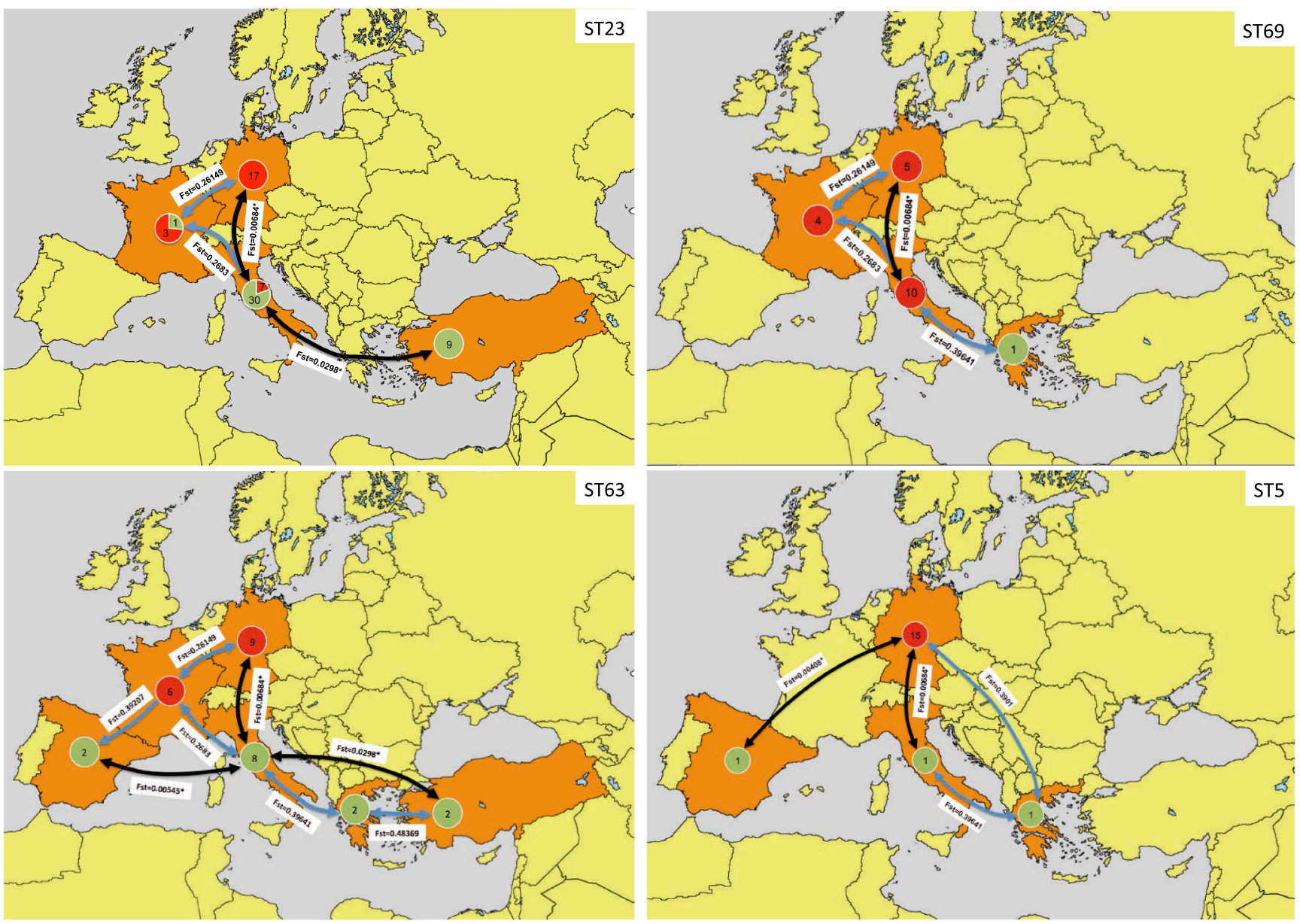

Fig. 8. Maps representing the main genetic flux directions between European and Mediterranean countries. Pairwise $F_{S T}$ test was calculated by DNAsp v5.10.1 and is reported on each arrow. Asterisk indicates that the genetic flux is supported by statistical analysis ( $<<0.05)$. The most probable spreading directions for ST5, ST23, ST63, and ST69 (the most prevalent genotypes in Europe) are indicated as black arrows. Light blue arrows represent alternative spreading directions not supported by statistical analysis. Green circles represent environmental isolates and red circles the clinical ones. The number in each circle is the number of isolates. (For interpretation of the references to colour in this figure legend, the reader is referred to the web version of this article.)

detailed genetic population analysis of the two groups of isolates due to the abundance of VNIV isolates in Europe and a wide environmental survey recently carried out on the continent (Cogliati et al., 2016a) that allowed several environmental isolates to be collected.

Genetic flow analysis of the most prevalent VNI genotypes in Europe showed that four main STs are spreading in Europe (ST23, ST63, ST69, and ST5). Germany and Italy seem to be the main fulcrum of diffusion of both endemic (ST23 and ST63) and imported genotypes of the $C$. neoformans species complex genotypes (ST69 and ST5). More detailed investigations are needed to understand the mechanisms by which this pathogen has crossed continents to and from Europe.

Finally, the 15 environmental C. gattii VGI and the unique VGIV isolates investigated in the present study provided further evidence of the endemic presence of these fungi in the Mediterranean area, confirming the results previously reported by Hagen et al. (2012) which identified a cluster containing most of the VGI isolates reported from Europe. Furthermore, our study observed that in Europe ST156 is the most frequent VGI genotype belonging to a wider CC present in Italy and Spain, whereas another CC (CC204) seems to be located in Greece.

Although this study provides new insights about molecular epidemiology and population genetics of $C$. neoformans and C. gattii species complexes, it is difficult to give an exhaustive picture of the situation in Europe due to the following limits: (a) thousands of Cryptococcus isolates have been isolated in Europe but at present only 6\% of isolates have been genotyped by MLST (Cogliati, 2013); (b) the sequenced isolates were reported from only a few European and Mediterranean countries but for most of the other European countries data are lacking; (c) about $16 \%$ of European isolates are $\mathrm{AD}$ hybrids and little is known about their genotypes; (d) environmental isolates represent a small percentage $(10 \%)$ of the total number of isolates available (Cogliati, 2013). These limits make this study a preliminary study and should be considered a basis for future investigations. Future efforts to overcome these limitations should be carried out in order to elucidate the real epidemiology of Cryptococcus and cryptococcosis in Europe and in the Mediterranean area.

In conclusion, by genetic investigation of environmental populations of Cryptococcus neoformans and Cryptococcus gattii species complexes, our study has revealed that clinical and environmental isolates in this collection of 467 isolates have different genotypic features. This approach is a first step to understanding the genetic characteristics that cause the shift of some genotypes from a saprophytic to a parasitic life style.

\section{Conflicts of interests}

All authors declare no conflicts of interests.

\section{Acknowledgments}

We thank Dr. Kwon Chung and Prof. Dromer for contribution in the critical reading of the manuscript.

The findings and conclusions in this manuscript are those of the 
authors and do not necessarily represent the official position of the Centers for Disease Control and Prevention.

W Meyer and S Lockhart were supported by an NH\&MRC grant \# APP1031943.

AC Sampaio was supported by Fundação para a Ciência e Tecnologia and FEDER/COMPETE/POCI provided to CITAB under the projects POCI-01-0145-FEDER-006958 and UID/AGR/04033/2019.

A Velegraki was supported by SARG K.A.70/4/5905 and 70/3/ 6915, National and Kapodistrian University of Athens and the Bodosakis Foundation, Athens, Greece.

\section{References}

Bartlett, K.H., Cheng, P.Y., Duncan, C., Galanis, E., Hoang, L., Kidd, S., Lee, M.K., Lester, S., MacDougall, L., Mak, S., Morshed, M., Taylor, M., Kronstad, J., 2012. A decade of experience: Cryptococcus gattii in British Columbia. Mycopathologia 173, 311-319.

Billmyre, R.B., Croll, D., Li, W., Mieczkowski, P., Carter, D.A., Cuomo, C.A., Kronstad, J.W., Heitman, J., 2014. Highly recombinant VGII Cryptococcus gattii population develops clonal outbreak clusters through both sexual macroevolution and asexual microevolution. MBio 5, e01494-e1514.

Chen, S.C., Meyer, W., Sorrell, T.C., 2014. Cryptococcus gattii infections. Clin. Microbiol. Rev. 27, 980-1024.

Chowdhary, A., Randhawa, H.S., Boekhout, T., Hagen, F., Klaassen, C.H., Meis, J.F., 2012. Temperate climate niche for Cryptococcus gattii in Northern Europe. Emerg. Infect. Dis. $18,172-174$.

Cogliati, M., Chandrashekar, N., Esposto, M.C., Chandramuki, A., Petrini, B., Viviani, M.A., 2012a. Cryptococcus gattii serotype-C strains isolated in Bangalore, Karnataka, India. Mycoses 55, 262-268.

Cogliati, M., Barchiesi, F., Spreghini, E., Tortorano, A.M., 2012b. Heterozygosis and pathogenicity of Cryptococcus neoformans AD-hybrid isolates. Mycopathologia 173, 347-355.

Cogliati, M., D'Amicis, R., Zani, A., Montagna, M.T., Caggiano, G., De Giglio, O., Balbino, S., De Donno, A., Serio, F., Susever, S., Ergin, C., Velegraki, A., Ellabib, M.S., Nardoni, S., Macci, C., Oliveri, S., Trovato, L., Dipineto, L., Rickerts, V., McCormick-Smith, I., Akcaglar, S., Tore, O., Mlinaric-Missoni, E., Bertout, S., Mallié, M., Martins Mda, L., Vencà, A.C., Vieira, M.L., Sampaio, A.C., Pereira, C., Criseo, G., Romeo, O., Ranque, S., Al-Yasiri, M.H., Kaya, M., Cerikcioglu, N., Marchese, A., Vezzulli, L., Ilkit, M., Desnos-Ollivier, M., Pasquale, V., Korem, M., Polacheck, I., Scopa, A., Meyer, W., Ferreira-Paim, K., Hagen, F., Theelen, B., Boekhout, T., Lockhart, S.R., Tintelnot, K., Tortorano, A.M., Dromer, F., Varma, A., Kwon-Chung, K.J., Inácio, J., Alonso, B., Colom, M.F., 2016a. Environmental distribution of Cryptococcus neoformans and C. gattii around the Mediterranean basin. FEMS Yeast Res. 16 pii: fow045.

Cogliati, M., Puccianti, E., Montagna, M.T., De Donno, A., Susever, S., Ergin, C., Velegraki, A., Ellabib, M.S., Nardoni, S., Macci, C., Trovato, L., Dipineto, L., Rickerts, V., Akcaglar, S., Mlinaric-Missoni, E., Bertout, S., Vencà, A.C.F., Sampaio, A.C., Criseo, G., Ranque, S., Çerikçioğlu, N., Marchese, A., Vezzulli, L., Ilkit, M., DesnosOllivier, M., Pasquale, V., Polacheck, I., Scopa, A., Meyer, W., Ferreira-Paim, K., Hagen, F., Boekhout, T., Dromer, F., Varma, A., Kwon-Chung, K.J., Inácio, J., Colom, M.F., 2017. Fundamental niche prediction of the pathogenic yeasts Cryptococcus neoformans and Cryptococcus gattii in Europe. Environ. Microbiol. 19, 4318-4325.

Cogliati, M., Zamfirova, R.R., Tortorano, A.M., Viviani, M.A., 2013. Fimua Cryptococcosis Network. Molecular epidemiology of Italian clinical Cryptococcus neoformans var. grubii isolates. Med. Mycol. 51, 499-506.

Cogliati, M., Zani, A., Rickerts, V., McCormick, I., Desnos-Ollivier, M., Velegraki, A., Escandon, P., Ichikawa, T., Ikeda, R., Bienvenu, A.L., Tintelnot, K., Tore, O. Akcaglar, S., Lockhart, S., Tortorano, A.M., Varma, A., 2016b. Multilocus sequence typing analysis reveals that Cryptococcus neoformans var. neoformans is a recombinant population. Fungal Genet. Biol. 87, 22-29.

Cogliati, M., 2013. Global molecular epidemiology of Cryptococcus neoformans and Cryptococcus gattii: an atlas of the molecular types. Scientifica (Cairo). 2013, 675213.

Colom, M.F., Hagen, F., Gonzalez, A., Mellado, A., Morera, N., Linares, C., García, D.F., Peñataro, J.S., Boekhout, T., Sánchez, M., 2012. Ceratonia siliqua (carob) trees as natural habitat and source of infection by Cryptococcus gattii in the Mediterranean environment. Med. Mycol. 50, 67-73.

Danesi, P., Firacative, C., Cogliati, M., Otranto, D., Capelli, G., Meyer, W., 2014. Multilocus sequence typing (MLST) and M13 PCR fingerprinting revealed heterogeneity amongst Cryptococcus species obtained from Italian veterinary isolates. FEMS Yeast Res. 14, 897-909.

Desnos-Ollivier, M., Patel, S., Raoux-Barbot, D., Heitman, J., Dromer, F., French Cryptococcosis Study Group, 2015. Cryptococcosis serotypes impact outcome and provide evidence of Cryptococcus neoformans speciation. MBio (6), e00311.

Dioverti, M.V., Parikh, S.A., Osmon, D.R., Habermann, T.M., Tande, A.J., 2018. Cryptococcus neoformans infections in patients with lymphoproliferative neoplasms. Leuk. Lymphoma. https://doi.org/10.1080/10428194.2018.

Engelthaler, D.M., Hicks, N.D., Gillece, J.D., Roe, C.C., Schupp, J.M., Driebe, E.M., Gilgado, F., Carriconde, F., Trilles, L., Firacative, C., Ngamskulrungroj, P., Castañeda, E., Lazera Mdos, S., Melhem, M.S., Pérez-Bercoff, A., Huttley, G., Sorrell, T.C., Voelz, K., May, R.C., Fisher, M.C., Thompson 3rd, G.R., Lockhart, S.R., Keim, P., Meyer, W., 2014. Cryptococcus gattii in North American Pacific Northwest: whole-population genome analysis provides insights into species evolution and dispersal. mBio 5, e01464-e1514.

Ferreira-Paim, K., Andrade-Silva, L., Fonseca, F.M., Ferreira, T.B., Mora, D.J., Andrade-
Silva, J., Khan, A., Dao, A., Reis, E.C., Almeida, M.T., Maltos, A., Junior, V.R., Trilles, L., Rickerts, V., Chindamporn, A., Sykes, J.E., Cogliati, M., Nielsen, K., Boekhout, T., Fisher, M., Kwon-Chung, J., Engelthaler, D.M., Lazéra, M., Meyer, W., 2017. SilvaVergara ML. MLST-Based Population genetic analysis in a global context reveals clonality amongst Cryptococcus neoformans var. grubii VNI isolates from HIV patients in Southeastern Brazil. PLoS Negl. Trop. Dis. 11, e0005223.

Firacative, C., Roe, C.C., Malik, R., Ferreira-Paim, K., Escandón, P., Sykes, J.E., CastañónOlivares, L.R., Contreras-Peres, C., Samayoa, B., Sorrell, T.C., Castañeda, E., Lockhart, S.R., Engelthaler, D.M., Meyer, W., 2016. MLST and Whole-genome-based population analysis of Cryptococcus gattii VGIII links clinical, veterinary and environmental strains, and reveals divergent serotype specific sub-populations and distant ancestors. PLoS Negl. Trop. Dis. 10, e0004861.

Florentino, I.S.M., Júnior, J.B.D., Cantilino, A., 2018. Neurocryptococcosis in immunocompetent patient with psychosis. Clin. Schizophr. Relat. Psychoses. https:// doi.org/10.3371/CSRP.FLJU.061518.

George, I.A., Spec, A., Powderly, W.G., Santos, C.A.Q., 2018. Comparative Epidemiology and Outcomes of Human Immunodeficiency virus (HIV), Non-HIV non-transplant, and solid organ transplant associated cryptococcosis: a population-based Study. Clin. Infect. Dis. 66, 608-611.

Hagen, F., Ceresini, P.C., Polacheck, I., Ma, H., van Nieuwerburgh, F., Gabaldón, T., Kagan, S., Pursall, E.R., Hoogveld, H.L., van Iersel, L.J., Klau, G.W., Kelk, S.M., Stougie, L., Bartlett, K.H., Voelz, K., Pryszcz, L.P., Castañeda, E., Lazera, M., Meyer, W., Deforce, D., Meis, J.F., May, R.C., Klaassen, C.H., Boekhout, T., 2013. Ancient dispersal of the human fungal pathogen Cryptococcus gattii from the Amazon rainforest. PLOS ONE 8, e71148.

Hagen, F., Colom, M.F., Swinne, D., Tintelnot, K., Iatta, R., Montagna, M.T., TorresRodriguez, J.M., Cogliati, M., Velegraki, A., Burggraaf, A., Kamermans, A., Sweere, J.M., Meis, J.F., Klaassen, C.H., Boekhout, T., 2012. Autochthonous and dormant Cryptococcus gattii infections in Europe. Emerg. Infect. Dis. 18, 1618-1624.

Hagen, F., Khayhan, K., Theelen, B., Kolecka, A., Polacheck, I., Sionov, E., Falk, R., Parnmen, S., Lumbsch, H.T., Boekhout, T., 2015. Recognition of seven species in the Cryptococcus gattii/Cryptococcus neoformans species complex. Fungal Genet. Biol. 78, $16-48$.

Hagen, F., Lumbsch, H.T., Arsic-Arsenijevic, V., Badali, H., Bertout, S., Billmyre, R.B. Bragulat, M.R., Cabañes, F.J., Carbia, M., Chakrabarti, A., Chaturvedi, S., Chaturvedi, V., Chen, M., Chowdhary, A., Colom, M.F., Cornely, O.A., Crous, P.W., Cuétara, M.S., Diaz, M.R., Espinel-Ingroff, A., Fakhim, H., Falk, R., Fang, W., Herkert, P.F., Ferrer Rodríguez, C., Fraser, J.A., Gené, J., Guarro, J., Idnurm, A., Illnait-Zaragozi, M.T., Khan, Z., Khayhan, K., Kolecka, A., Kurtzman, C.P., Lagrou, K., Liao, W., Linares, C., Meis, J.F., Nielsen, K., Nyazika, T.K., Pan, W., Pekmezovic, M., Polacheck, I., Posteraro, B., de Queiroz, Telles F., Filho, Romeo O., Sánchez, M., Sampaio, A. Sanguinetti, M., Sriburee, P., Sugita, T., Taj-Aldeen, S.J., Takashima, M., Taylor, J.W., Theelen, B., Tomazin, R., Verweij, P.E., Wahyuningsih, R., Wang, P., Boekhout, T., 2017. Importance of resolving fungal nomenclature: the case of multiple pathogenic species in the Cryptococcus genus. mSphere 2 pii: e00238-17.

Hagen, F., van Assen, S., Luijckx, G.J., Boekhout, T., Kampinga, G.A., 2010. Activated dormant Cryptococcus gattii infection in a Dutch tourist who visited Vancouver Island (Canada): a molecular epidemiological approach. Med. Mycol. 48, 528-531.

Hamdan, N., Billon Grand, R., Moreau, J., Thines, L., 2018. Cryptococcal meningitis in an immunocompetent patient with obstructive hydrocephalus: a case report. Neurochirurgie 64, 324-326.

Henao-Martínez, A.F., Chastain, D.B., Franco-Paredes, C., 2018. Treatment of cryptococcosis in non-HIV immunocompromised patients. Curr. Opin. Infect. Dis. 31, 278-285.

Khayhan, K., Hagen, F., Pan, W., Simwami, S., Fisher, M.C., Wahyuningsih, R., Chakrabarti, A., Chowdhary, A., Ikeda, R., Taj-Aldeen, S.J., Khan, Z., Ip, M., Imran, D., Sjam, R., Sriburee, P., Liao, W., Chaicumpar, K., Vuddhakul, V., Meyer, W., Trilles, L., van Iersel, L.J., Meis, J.F., Klaassen, C.H., Boekhout, T., 2013. Geographically structured populations of Cryptococcus neoformans variety grubii in Asia correlate with HIV status and show a clonal population structure. PLOS ONE 8, e72222.

Kwon-Chung, K.J., Bennett, J.E., Wickes, B.L., Meyer, W., Cuomo, C.A., Wollenburg, K.R., Bicanic, T.A., Castañeda, E., Chang, Y.C., Chen, J., Cogliati, M., Dromer, F., Ellis, D., Filler, S.G., Fisher, M.C., Harrison, T.S., Holland, S.M., Kohno, S., Kronstad, J.W., Lazera, M., Levitz, S.M., Lionakis, M.S., May, R.C., Ngamskulrongroj, P., Pappas, P.G., Perfect, J.R., Rickerts, V., Sorrell, T.C., Walsh, T.J., Williamson, P.R., Xu, J., Zelazny, A.M., Casadevall, A., 2017. The case for adopting the "species complex" nomenclature for the etiologic agents of cryptococcosis. mSphere 2 pii: e00357-16.

Kwon-Chung, K.J., Fraser, J.A., Doering, T.L., Wang, Z., Janbon, G., Idnurm, A., Bahn, Y.S., 2014. Cryptococcus neoformans and Cryptococcus gattii, the etiologic agents of cryptococcosis. Cold Spring Harb. Perspect. Med. 4, a019760.

Linares, C., Colom, M.F., Torreblanca, M., Esteban, V., Romera, Á., Hagen, F., 2015. Environmental sampling of Ceratonia siliqua (carob) trees in Spain reveals the presence of the rare Cryptococcus gattii genotype AFLP7/VGIV. Rev. Iberoam. Micol. 32, 269-272.

Mak, S., Klinkenberg, B., Bartlett, K., Fyfe, M., 2010. Ecological niche modeling of Cryptococcus gattii in British Columbia, Canada. Environ. Health Perspect. 118 653-658.

Meyer, W., Aanensen, D.M., Boekhout, T., Cogliati, M., Diaz, M.R., Esposto, M.C., Fisher, M., Gilgado, F., Hagen, F., Kaocharoen, S., Litvintseva, A.P., Mitchell, T.G., Simwami, S.P., Trilles, L., Viviani, M.A., Kwon-Chung, J., 2009. Consensus multi-locus sequence typing scheme for Cryptococcus neoformans and Cryptococcus gattii. Med. Mycol. 47, 561-570.

Meyer, W., Castañeda, A., Jackson, S., Huynh, M., Castañeda, E., IberoAmerican Cryptococcal Study Group, 2003. Molecular typing of IberoAmerican Cryptococcus neoformans isolates. Emerg. Infect. Dis. 9, 189-195. 
Miranda-Filho, A., Piñeros, M., Ferlay, J., Soerjomataram, I., Monnereau, A., Bray, F., 2018. Epidemiological patterns of leukaemia in 184 countries: a population-based study. Lancet Haematol. 5, e14-e24.

Montagna, M.T., De Donno, A., Caggiano, G., Serio, F., De Giglio, O., Bagordo, F., D'Amicis, R., Lockhart, S.R., Cogliati, M., 2018. Molecular characterization of Cryptococcus neoformans and Cryptococcus gattii from environmental sources and genetic comparison with clinical isolates in Apulia, Italy. Environ. Res. 160, 347-352.

Morse, J.C., Gelbard, A., 2018. Laryngeal cryptococcoma resulting in airway compromise in an immunocompetent patient: a case report. Laryngoscope. https://doi.org/10. 1002/lary.27456.

Muñoz, M., Camargo, M., Ramírez, J.D., 2018. Estimating the intra-taxa diversity, population genetic structure, and evolutionary pathways of Cryptococcus neoformans and Cryptococcus gattii. Front. Genet. 9, 148

Nyazika, T.K., Hagen, F., Meis, J.F., Robertson, V.J., 2016. Cryptococcus tetragattii as a major cause of cryptococcal meningitis among HIV-infected individuals in Harare, Zimbabwe. J. Infect. 72, 745-752.

Pappas, P.G., 2013. Cryptococcal infections in non-HIV-infected patients. Trans. Am. Clin. Climatol. Assoc. 124, 61-79.

Posteraro, P., Vacca, K., Celi, M., De Angelis, G., Vella, A., Sanguinetti, M., Posteraro, B., 2018. Fatal fulminant cryptococcemia complicating sarcoidosis: Is it to be expected? Med. Mycol. Case Rep. 22, 42-44.

Rhodes, J., Desjardins, C.A., Sykes, S.M., Beale, M.A., Vanhove, M., Sakthikumar, S., Chen, Y., Gujja, S., Saif, S., Chowdhary, A., Lawson, D.J., Ponzio, V., Colombo, A.L., Meyer, W., Engelthaler, D.M., Hagen, F., Illnait-Zaragozi, M.T., Alanio, A., Vreulink, J.M., Heitman, J., Perfect, J.R., Litvintseva, A.P., Bicanic, T., Harrison, T.S., Fisher, M.C., Cuomo, C.A., 2017. Tracing genetic exchange and biogeography of Cryptococcus neoformans var. grubii at the global population level. Genetics 207, 327-346.

Roe, C.C., Bowers, J., Oltean, H., DeBess, E., Dufresne, P.J., McBurney, S., Overy, D.P., Wanke, B., Lysen, C., Chiller, T., Meyer, W., Thompson 3rd, G.R., Lockhart, S.R., Hepp, C.M., Engelthaler, D.M., 2018. Dating the Cryptococcus gattii dispersal to the North American Pacific Northwest. mSphere 3 pii: e00499-17.

Samarasinghe, H., Aceituno-Caicedo, D., Cogliati, M., Kwon-Chung, K.J., Rickerts, V., Velegraki, A., Ackaglar, S., Xu, J., 2018. Genetic factors and genotype-environmen interactions contribute to variation in melanin production in the fungal pathogen
Cryptococcus neoformans. Sci. Rep. 8, 9824

Sanchini, A., Smith, I.M., Sedlacek, L., Schwarz, R., Tintelnot, K., Rickerts, V., 2014. Molecular typing of clinical Cryptococcus neoformans isolates collected in Germany from 2004 to 2010. Med. Microbiol. Immunol. 203, 333-340.

Shahid, M., Han, S., Yoell, H., Xu, J., 2008. Fitness distribution and transgressive segregation across 40 environments in a hybrid progeny population of the human-pathogenic yeast Cryptococcus neoformans. Genome 51, 272-281.

Shuai, S.Y., Xiong, L., He, X.L., Yu, F., Xia, Q., Zhou, Q., 2018. A unique case report of endobronchial cryptococcosis and review of the literature. Respir. Med. Case Rep. 25, $247-252$.

Souto, A.C., Bonfietti, L.X., Ferreira-Paim, K., Trilles, L., Martins, M., Ribeiro-Alves, M., Pham, C.D., Martins, L., Dos Santos, W., Chang, M., Brito-Santos, F., Santos, D.C., Fortes, S., Lockhart, S.R., Wanke, B., Melhem, M.S., Lazéra, M.S., Meyer, W., 2016. Population genetic analysis reveals a high genetic diversity in the Brazilian Cryptococcus gattii VGII population and shifts the global origin from the Amazon rainforest to the semi-arid desert in the Northeast of Brazil. PLoS Negl. Trop. Dis. 10, $\mathrm{e} 0004885$.

Sun, S., Xu, J., 2009. Chromosomal rearrangements between serotype A and D strains in Cryptococcus neoformans. PLoS ONE 4, e5524.

Swan, C.D., Gottlieb, T., 2018. Cryptococcus neoformans empyema in a patient receiving ibrutinib for diffuse large B-cell lymphoma and a review of the literature. BMJ Case Rep. 2018 pii: bcr-2018-224786.

Viviani, M.A., Cogliati, M., Esposto, M.C., Lemmer, K., Tintelnot, K., Colom Valiente, M.F., Swinne, D., Velegraki, A., Velho, R., European Confederation of Medical Mycology (ECMM) Cryptococcosis Working Group, 2006. Molecular analysis of 311 Cryptococcus neoformans isolates from a 30-month ECMM survey of cryptococcosis in Europe. FEMS Yeast Res. 6, 614-619.

Wang, Q., Wang, Z., Hao, Y., Li, W., Xin, T., Chen, M., Gao, P., 2018. Coinfection with Cryptococcus and Aspergillus in an immunocompetent adult: a case report. Medicine (Baltimore) 97, e12612.

Yamada, W., Yamada, H., Murata, K., Kosugi, H., Asano, Y., Mochizuki, K., Ishida, K., 2018. Case of cryptococcal choroiditis in adult with T-cell leukemia/lymphoma. J. Infect. Chemother pii: S1341-321X(18)30190-9. 